\title{
Unraveling Muscle Impairment Associated With COVID-19 and the Role of 3D Culture in Its Investigation
}

\section{OPEN ACCESS}

Edited by:

Caterina Conte,

Università telematica San

Raffaele, Italy

Reviewed by:

Yoshitaka Hashimoto,

Kyoto Prefectural University of

Medicine, Japan

Mark Hamrick,

Augusta University, United States

${ }^{*}$ Correspondence:

Roberta Sessa Stilhano

roberta.yamaguchi@

fcmsantacasasp.edu.br

†These authors have contributed equally to this work

Specialty section: This article was submitted to

Clinical Nutrition,

a section of the journa

Frontiers in Nutrition

Received: 30 November 2021

Accepted: 18 January 2022

Published: 10 February 2022

Citation:

Seixas MLGA, Mitre LP, Shams S,

Lanzuolo GB, Bartolomeo CS,

Silva EA, Prado CM, Ureshino $R$ and Stilhano RS (2022) Unraveling Muscle

Impairment Associated With

COVID-19 and the Role of 3D Culture

in Its Investigation.

Front. Nutr. 9:825629.

doi: 10.3389/fnut.2022.825629
Maria Luiza G. A. Seixas ${ }^{1+}$, Lucas Pari Mitre ${ }^{1+}$, Shahin Shams ${ }^{2}$, Gabriel Barbugian Lanzuolo ${ }^{1}$, Cynthia Silva Bartolomeo ${ }^{1,3}$, Eduardo A. Silva ${ }^{2}$, Carla Maximo Prado ${ }^{3}$, Rodrigo Ureshino ${ }^{4}$ and Roberta Sessa Stilhano ${ }^{1 *}$

'Department of Physiological Sciences, Santa Casa de São Paulo School of Medical Sciences, São Paulo, Brazil, ${ }^{2}$ Department of Biomedical Engineering, University of California, Davis, Davis, CA, United States, ${ }^{3}$ Department of Biosciences, Federal University of São Paulo, São Paulo, Brazil, ${ }^{4}$ Department of Biological Sciences, Federal University of São Paulo, São Paulo, Brazil

COVID-19, caused by severe acute respiratory syndrome coronavirus 2 (SARS-CoV-2), has been considered a public health emergency, extensively investigated by researchers. Accordingly, the respiratory tract has been the main research focus, with some other studies outlining the effects on the neurological, cardiovascular, and renal systems. However, concerning SARS-CoV-2 outcomes on skeletal muscle, scientific evidence is still not sufficiently strong to trace, treat and prevent possible muscle impairment due to the COVID-19. Simultaneously, there has been a considerable amount of studies reporting skeletal muscle damage in the context of COVID-19. Among the detrimental musculoskeletal conditions associated with the viral infection, the most commonly described are sarcopenia, cachexia, myalgia, myositis, rhabdomyolysis, atrophy, peripheral neuropathy, and Guillain-Barré Syndrome. Of note, the risk of developing sarcopenia during or after COVID-19 is relatively high, which poses special importance to the condition amid the SARS-CoV-2 infection. The yet uncovered mechanisms by which musculoskeletal injury takes place in COVID-19 and the lack of published methods tailored to study the correlation between COVID-19 and skeletal muscle hinder the ability of healthcare professionals to provide SARS-CoV-2 infected patients with an adequate treatment plan. The present review aims to minimize this burden by both thoroughly exploring the interaction between COVID-19 and the musculoskeletal system and examining the cutting-edge 3D cell culture techniques capable of revolutionizing the study of muscle dynamics.

Keywords: skeletal muscle, COVID-19, SARS-CoV-2, inflammation, biomaterials

\section{INTRODUCTION}

In December 2019, a novel coronavirus designated as "SARS-CoV-2" emerged in Wuhan, China. A few months after the virus' advent, the World Health Organization (WHO) declared COVID-19, the disease caused by SARS-CoV-2, a pandemic (1). The virus has rapidly spread across the globe, having surpassed 250 million cases and 5 million deaths as of 14 November 2021 (2). SARS-CoV-2 predominantly infects the airways, yielding symptoms related to mild respiratory infections and, in severe cases, acute respiratory syndrome (3). Therefore, the 
respiratory tract was established as the main SARS-CoV-2 infection focus and, consequently, has been the primary system studied in medical research endeavors.

However, as both the pandemic and scientific research advanced, new SARS-CoV-2 infection hotspots beyond the nasal cavity, throat, and lungs were identified. The blood, brain, heart, and kidneys are examples of systems extensively studied in the context COVID-19 effects. Excessive inflammation, hypoxia, hypercoagulability are among the main reasons that explain these extra-respiratory manifestations of COVID-19 (4-6). Nevertheless, at present, minimal attention has been given to the effect of COVID-19 on skeletal muscle.

As one of the most abundant tissue types in the human body, skeletal muscle is of paramount importance in guaranteeing one's autonomy of movement and independence in daily activities. Damage to the musculoskeletal system is associated with increased Disability-Adjusted Life Years (DALYs) and injury chronification (7), which highlights the importance of skeletal muscle on the quality of life of individuals.

It is now well established that COVID-19 is intrinsically related to several musculoskeletal deteriorating conditions. Clinical observations have revealed that SARS-CoV-2 patients are at high risk of developing sarcopenia acutely or insidiously (8), as well as some degree of cachexia (9). Myalgia has been indicated as the third most common symptom in symptomatic infected patients (10). Myositis, rhabdomyolysis (9), and skeletal muscle atrophy (11) are other disorders deeply associated with the SARS-CoV-2 infection. Lastly, a few neuromuscular disorders have also been reported in COVID-19, including peripheral neuropathy (12) and Guillain-Barre Syndrome (13). Mechanisms that explain why these disorders commonly develop in the setting of COVID-19 are still lacking, but SARS-CoV-2 induced cytokine storm seems to be one of the main reasons that justify it.

The uncertainty surrounding COVID-19's impact on skeletal muscle has been hampering medical treatment concerning the musculoskeletal system during the pandemic. There is therefore a pronounced necessity to elucidate the mechanisms of SARS$\mathrm{CoV}-2$ infection and skeletal muscle. In this context, the study of muscle tissue dynamics during both COVID-19 and recovery becomes imperative. The present study, thus, intends not only to investigate deeply how SARS-CoV-2 interacts with and injures the skeletal muscle but also to detail state-of-the-art cell culture methods, mainly 3D cultures, that could be largely used to study muscle dynamics.

\section{COVID-19 AND ITS EFFECT ON SKELETAL MUSCLE}

\section{Viral Infections Overview}

The study of tissue-specific viral kinetics and replication mechanics is of paramount importance when analyzing the viral impact on each individual tissue. It was recently detected that the differentiation state of skeletal muscle cellular components significantly impacts the ability to resist viral infection in an experimental ZIKV infection model (14). It was suggested that skeletal muscle differentiation could induce changes in cellular factors, predisposing to viral infection in the organ (14). This may be possible due to preferential tropism interactions of specific viruses to replicating cells. Moreover, as fully differentiated cells, skeletal muscle fibers are quiescent, which may lead to partial resistance to viral infection. This phenomenon is well documented in the viral infection setting in regenerative therapy strategies with integrative viruses. Thus, this aspect of modified resistance to certain viral infections may spur an interesting insight when theorizing possible skeletal muscle susceptibility to direct SARS-CoV-2 infection. It is rational to suppose that myoblast (15) would be the primary target of COVID-19, as they are actively replicating, as opposed to myofibers and MuSCs (Muscle Stem Cells), which replicate only under specific conditions. This would further contribute to a loss of regenerative abilities of the skeletal muscle in the vicinity of infection, as myoblasts are essential in the musculoskeletal repair, once they differentiate and donate cellular and nuclear components to structure ruptured fibers (16).

Viruses enter susceptible cells through different mechanisms, such as cell adhesion and interaction with specific receptors, which is followed by invasion through endocytosis and fusion (17). Previous studies of viral diseases have indicated that the mode of cellular infection is related to the tropism of the virus (18-20). Certain viruses, such as HCV, CHIKV, and ZIKV have a tropism for the skeletal muscle or show signs of direct invasion and impairment in anatomopathological studies, such as a few with SARS-CoV-1 and MERS (21, 22). SARS-CoV-1 and MERS infections result in an atrophic profile of skeletal muscle degeneration associated with focal necrosis and $\mathrm{Z}$ disc streaming. This report suggests that SARSCoV-1 and MERS infection impacts skeletal muscle via direct viral invasion. On the other hand, immune cell infiltration, myositis, and macrophages with viral particles confirm a systemic impairment to skeletal muscle secondary to immunological deterioration. The fact that other RNA viruses, such as influenza virus and $\mathrm{HCV}$, may produce skeletal muscle fiber focal necrosis in a similar way sheds light on the importance of studying RNA viruses' mechanism of skeletal muscle impairment $(18,22)$.

However, tissue-specific harm in the onset of viral infections may not always be distinguishable from systemic inflammation, an indirect impact as they are concurrent phenomena. The agerelated immunological decline, for instance, marked, among other characteristics, by loss of phagocytic function and loss of MuSCs and FAP (fibroadipogenic progenitors) proliferation, is a central factor that hinders distinction between both phenomena (18). For example, it has been demonstrated that clinical musculoskeletal deficiencies and myofiber stress are still present in HIV patients, even after viral levels are undetectable (23). Thus, viral infections, such as HIV, exemplify how skeletal muscle can be impaired either through direct or systemic conditions. 


\section{SARS-CoV-2 Investigation: SARS-CoV-2 Mechanism of Action and Skeletal Muscle Viral Entrance}

SARS-CoV-2 is a positive-sense single-stranded RNA virus, member of the coronavirus family. Cellular entry mechanisms of coronaviruses hinge on the binding of spike (S) protein to a specific cellular receptor, which triggers $S$ protein priming by cellular proteases (24), a process that allows further viral spread.

On mature viruses, the $S$ protein is a trimer composed of three receptor-binding S1 heads placed on top of a trimeric membrane fusion S2 stalk. S1 carries a receptor-binding domain (RBD) that recognizes angiotensin-converting enzyme 2 (ACE2) as its receptor (25). Interestingly, RBD's conformation constantly changes in order to favor virus activity in host cells: it acquires a standing-up position to allow receptor binding and a lyingdown position to allow immune evasion (26). Further membrane fusion between the host cell and the virus occurs by a specific cleavage mechanism, mediated mainly by transmembrane serine protease 2 (TMPRSS2) and lysosomal proteases cathepsins (25): $S$ protein is activated proteolytically at the $\mathrm{S} 1 / \mathrm{S} 2$ boundary, which prompts S1 dissociation and S2 structural change $(27,28)$. Then, viral replication inside cells begins to occur (11).

The ACE2 receptor is widely expressed in the human body and the musculoskeletal system is not an exception. It has even been reported that the heart and skeletal muscle express ACE2 abundantly (29), which would raise the possibility of direct musculoskeletal damage seen in COVID-19 (which will be further discussed in detail) being intrinsically associated with ACE2 expression in the tissue.

The receptor is a multifunctional type I transmembrane metallocarboxypeptidase. Besides acting as a receptor for SARSCoV-2 entrance into human cells, it is also constitutionally associated with the renin-angiotensin-aldosterone system (RAS), responsible for blood pressure regulation (11). ACE2, due to its role in RAS and in other pathways that will be further outlined, acts as a protective component in the tissues where it is expressed. The binding of SARS-CoV-2 to ACE2 would thus impair the protective role of the receptor, which could, once more, contribute to the musculoskeletal damage seen in patients that experience COVID-19.

The need to study the SARS-CoV-2 mechanism of action in humans to combat the spread of the pandemic spurred the scientific community to compare the viral kinetics to other coronaviruses' kinetics, mainly SARS-CoV-1, with the principal aim of identifying possible uncovered processes that could support COVID-19 studies and clinical outcomes. In this context, the first key difference that was identified between both coronaviruses is associated with RBD. It is known that $\mathrm{RBD}$ conformation is dynamic, that is, it alters between two polar states of interaction with ACE2 (25). Interestingly, when comparing both viruses, SARS-CoV-1 was indicated as having a higher frequency of RBD in the standing-up position than SARS-CoV-2. This conformation allows the S1 spike subunit to be available for interaction and adhesion to human ACE2, which is, in turn, associated with infectivity. On the other hand, the affinity of RBD-human ACE2 binding was suggested to be higher in SARS-CoV-2. These apparently paradoxical results translate mechanistically to an enhanced immune evasion of SARS-CoV2: the main reasons being that in SARS-CoV-2, on top of the fact that RBD is less exposed when compared to SARS-CoVl's $\mathrm{RBD}$, it spends more time in the lying-down conformation, which makes it less detectable by immune cells and antibodies. This phenomenon alone would result in reduced infectivity of SARS-CoV-2. However, it is countered with a higher affinity of RBD-human ACE2 binding, which would enhance virus entry and compensate for immune evasion (25). As a consequence, on the whole, it is possible to conclude that SARS-CoV-2 has higher infectivity, as it is more efficient in perpetuating infection once in the human organism.

This rationale is similar for other coronaviruses, such as MERS-CoV, because $\mathrm{S}$ protein has been reported as its major surface antigen, and its RBD is endowed with the same flexibility, experiencing the same conformational changes described previously for SARS-CoV-1 and SARS-CoV-2 $(26,30)$. The presence of flexible RBD in coronaviruses is worrisome by itself, as it practically guarantees virus entry once receptor interaction is achieved (26). In conclusion, the particularities of SARS-CoV-2, a member of an already successful family of infective coronaviruses raise red flags as to a more efficient, and thus potentially harmful, mechanism of viral infection.

\section{ACE2 and RAS}

The ectodomain of ACE2 is primarily responsible for cleaving angiotensin II (Ang II) into Angiotensin 1-7 (Ang 1-7). As a multiple intracellular signaling pathway mediator, Ang 17 stimulates vasodilation, anti-proliferation, anti-inflammation, and anti-fibrosis processes: production of nitric oxide primarily via the AKT-eNOS pathway, inhibition of MAP kinase signaling (p38, ERK1/2, and JNK), suppression of reactive oxygen species (ROS) production by NADPH oxidases, inhibition of transforming growth factor beta (TGF- $\beta$ )-SMAD signaling, and modulation of cAMP signaling response. The fact that Ang 1-7 binds to Mas, MrgD (a member of Mas-related G-protein coupled receptors), and Ang II type 2 receptors allows it to exert its effect. It has also been suggested that alamandine, an endogenous peptide that is cleaved from angiotensin A by ACE2, binds to MrGD and provides protection similar to Ang 1-7 (31).

Under different pathological conditions, the ectodomain of ACE2 is shed by a disintegrin and metalloproteinase 17 (ADAM17), also known as tumor necrosis factor-alpha (TNF $\alpha$ )converting enzyme (TACE). This shedding process impairs ACE2 activity. In certain situations, such as inflammation, ADAM17 is increased (32), which would lead to decreased ACE2 activity in the setting of inflammatory states. The diminished activity of ACE2 would impair the protective role of the receptor, but, at the same time, could protect against COVID-19 infection, due to the fact that the virus enters the cell by ACE2 receptors. Further studies are required to investigate this dynamic.

In some comorbidities, such as diabetes, a systemic lower expression of ACE2 has been described (33). At the beginning of the SARS-CoV-2 pandemic, it was thought that this could represent protection once it meant fewer entrance receptors 
for the virus (33). Nevertheless, while the virus encounters fewer ACE2 receptors, the organism is also characterized by a suppressed ACE2-Ang1-7-Mas axis and an exacerbation of ACE-Ang II-AT1 axis, which ultimately represents a proinflammatory, pro-fibrosis, and pro-proliferation activity over an anti-inflammatory, anti-fibrosis, and anti-proliferation activity (34). Therefore, diabetic patients not only experience a state of low ACE2 because of their condition but also present a characteristic ACE2 downregulation due to virus entrance, which could, among other factors, contribute to why those patients have a worse COVID-19 prognosis than non-diabetic patients.

\section{ACE2, Ang II, and Ang 1-7 in Skeletal Muscle}

Ang II has been reported to hinder muscle protein synthesis mainly by inhibiting the insulin growth factor 1-AKTmammalian target of Rapamycin (IGF-1-AKT-mTOR) pathway, responsible for autophagy inhibition, energy homeostasis and structural plasticity (35). Ang II has also been shown to induce the up-regulation of atrogenes, especially MuRF-1 and atrogin-1, which are mainly responsible for ubiquitin-proteasomedependent protein breakdown and caspase-dependent myonuclear apoptosis. These processes spur the production of NOX2-dependent ROS production and induce $\mathrm{Nf} \kappa \mathrm{B}$ dependent inflammation and mitochondrial damage, which contribute to muscle fibrosis (34).

Ang 1-7 exerts a protective effect on skeletal muscle mainly due to the inhibition of Ang-II mechanisms of atrophy and fibrosis induction (34). Experimental Ang 1-7 infusions relieved muscle dysfunction in a few conditions, such as cancer cachexia (36), elevated concentrations of Ang II (37), atrophy induced by disuse $(38,39)$, and muscular dystrophy $(40,41)$. Conversely, it was seen that ACE2 overexpression and ensued augmented Ang 1-7 production that favors muscle dystrophy (42). However, the mechanism is yet to be confirmed (34).

Considering that SARS-CoV-2 entrance in cells occurs through ACE2 receptor, COVID-19 was already associated with a downregulation of ACE2 and a subsequent increase in Ang II levels and decrease in Ang 1-7 (43). Thus, on the whole, skeletal muscle in SARS-CoV-2 infected patients might be more susceptible to muscle damage.

\section{SARS-CoV-2 Induced Inflammation}

Upon entrance into the organism and its cells, it is known that SARS-CoV-2 triggers an aggressive inflammatory response that results in damage to multiple structures (44). Contrastingly, inflammation can act as a stimulating agent for skeletal muscle tissue recovery after lesion through a series of mechanisms (45, 46). This dynamic depends on the interaction between cellular, matrix, and circulatory components that orchestrates this process, maximizing the potential of recovery. During the SARSCoV-2 course of infection, what is seen in terms of systemic pro-recovery inflammation state is disrupted. It has already been established that the entry of the virus through the respiratory airways prompts a strong response to infection, provoking phenomenons of dysregulated immunological response, such as the cytokine storm (11). The cytokine storm is a potentially fatal condition caused by excessive liberation and activation of chemoattractant and inflammatory cytokines, products of interaction between the virus and the host's immune system (47). The storm of cytokines is also characterized by lymphopenia and excessive mononuclear cell infiltration in multiple tissues $(47,48)$. The enormous amount of inflammatory markers in the COVID-19 patient's blood have been linked to increased disease severity and hyperinflammation and increased neutrophil/lymphocyte ratio, with possible depletion of circulating T cells.

Possible mechanisms associated with T-cell depletion may be due to intense tissue recruitment as a consequence of excessive cytokine signaling (Figure 1). It is important to stress that immunological virus combating involves both innate and adaptive immune responses, and it is logical to expect disturbances in both domains when infections occur. It is possible for different organisms to have different types and intensities of innate/adaptive immune response based on each individual profile of response, and this may alter due to age and the development of medical conditions (49). People that tend to present mostly with the adaptive cellular response profile might have a stronger Th2 over Th1 response, which is especially true in infants. This has been correlated with a higher frequency of respiratory viral infections in children (not necessarily with disease severity) due to decreased production of cytokines crucial for viral clearance, such as IFN- $\gamma(49,50)$. In addition, viral clearance activity can occur without clinically detectable IgM and IgG, as phagocytic immune cells rapidly clear infected cells - impacting multiplicity of infection. It is possible to conclude that there are numerous possibilities when it comes to immunity development regarding SARS-CoV-2 infection, which has been proven by the myriad of clinical cases detected and mechanisms elucidated.

Possible hyperactive pathways related to pathological inflammation such as IL-6 signaling, TLR4-TRIF signaling, JAK-STAT signaling, CCR5, Complement component C5, and others are currently being investigated, but they have been solidly correlated hyperinflammation due to SARS-CoV-2 infection. These pathways, which mediate the response through the cytokines IFN- $\alpha / \gamma$, IL-1ß, IL- 6 , IL-12, TNF- $\alpha$, C-reactive protein (CRP), and components such as ferritin constitute proinflammatory routes that promote macrophage and natural killer (NK) cell activation, $\mathrm{T}$ cell recruitment, transcription of Interferon Stimulated Genes (ISGs) and inflammatory genes, inflammatory vascular mechanisms and immunological feedback loops; all phenomenons linked and potentially pathologically hyperactive in SARS-CoV-2 infection (47, 51-53) (Figure 1). It is interesting to observe that these major inflammatory pathways all derive from immunological mechanisms related to virus sensing through viral single-stranded RNA recognition, immunological recruitment, and activation subsequential to proinflammatory stimuli such as pathogen-associated molecular patterns (PAMPs), and overall increased cytokine production and liberation $(47,54)$. In conclusion, all prerequisites for harmful inflammatory cascade activation are fulfilled by SARSCoV-2 (Figure 1) and other viruses such as SARS-CoV-1 and MERS. In general, studying the immunological response to 


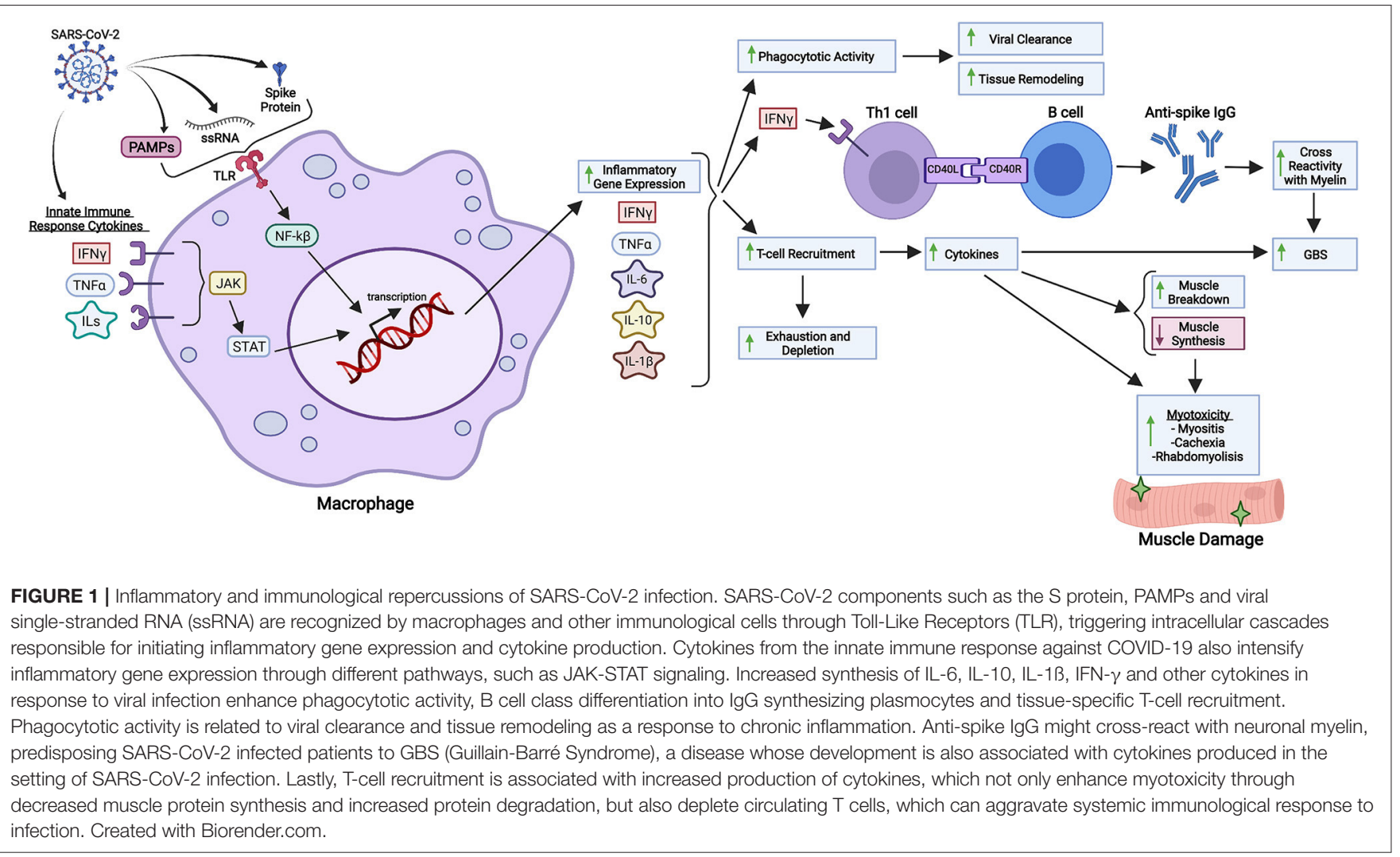

viruses provides a powerful perspective as to how viruses can trigger systemic inflammation.

\section{Main Musculoskeletal Complications Due to COVID-19}

\section{Sarcopenia}

It has become clear to the scientific community that patients that survive COVID-19 are at increased risk of acute sarcopenia and underlying muscle insufficiency (8). This is due to diminished ACE2 presence, inflammation, prolonged bedrest along with diminished physical activity, and hypoxia.

\section{ACE2 and Skeletal Muscle}

Several studies suggest that ACE2 plays a protective role against sarcopenia. Mice deficient in ACE2, G protein-coupled Apelin receptor (APLNR) and apelin have been shown to manifest accelerated sarcopenic phenotypes. These ACE2-knockout mice also exhibited a significant decrease in the essential amino acid tryptophan (Trp) in plasma and organs, including skeletal muscle (34). Considering that serum concentration of Trp was already associated with an increase in the volume of skeletal muscle in patients that present with diffuse large B-cell lymphoma (55), it is possible to state that ACE2-related-Trp-reduction may contribute to skeletal muscle volume diminishment, a clinical feature in sarcopenia. The same study also detected smaller tibialis anterior fiber diameters in Trp-deficient mice, comparing them to control mice (55).
COVID-19 has been associated with a downregulation of ACE2, partially motivated by viral infiltration through ACE2 receptors (43). Consequently, considering the sarcopeniarelated effects of ACE2 absence, the reduction in ACE2 in COVID-19 patients would contribute to sarcopenia (Figure 2).

\section{Inflammation}

It has been suggested that sarcopenia is intrinsically related to impaired immunity, as it was reported that the condition is associated with diminished proliferation of peripheral mononuclear cells, augmented ratio of neutrophils to lymphocytes, and damaged homeostasis of NK cells, which contributes to a state of immune senescence. The principal reason that justifies the impaired immunity in patients that experience sarcopenia is the presence of abnormal myokines, mainly IL-15, IL-17, and IL-6, responsible for modulating the proliferation and function of innate and adaptive immune cells (56). Along with immunity alterations, patients with sarcopenia also present with a state of metabolic stress, characterized by skeletal muscle catabolism with the aim of providing the immune system, liver, and gut with amino acids, mainly glutamine (56).

SARS-CoV-2 infection is initially characterized by a local inflammatory response that triggers the production of cytokines such as interferon- $\alpha$, interferon- $\gamma$, IL- 1 , IL- 6 , IL-12, TNF- $\alpha$, CRP, and monocyte chemotactic protein-1 $(56,57)$. Inflammation in the setting of COVID-19 was also reported to be associated with 


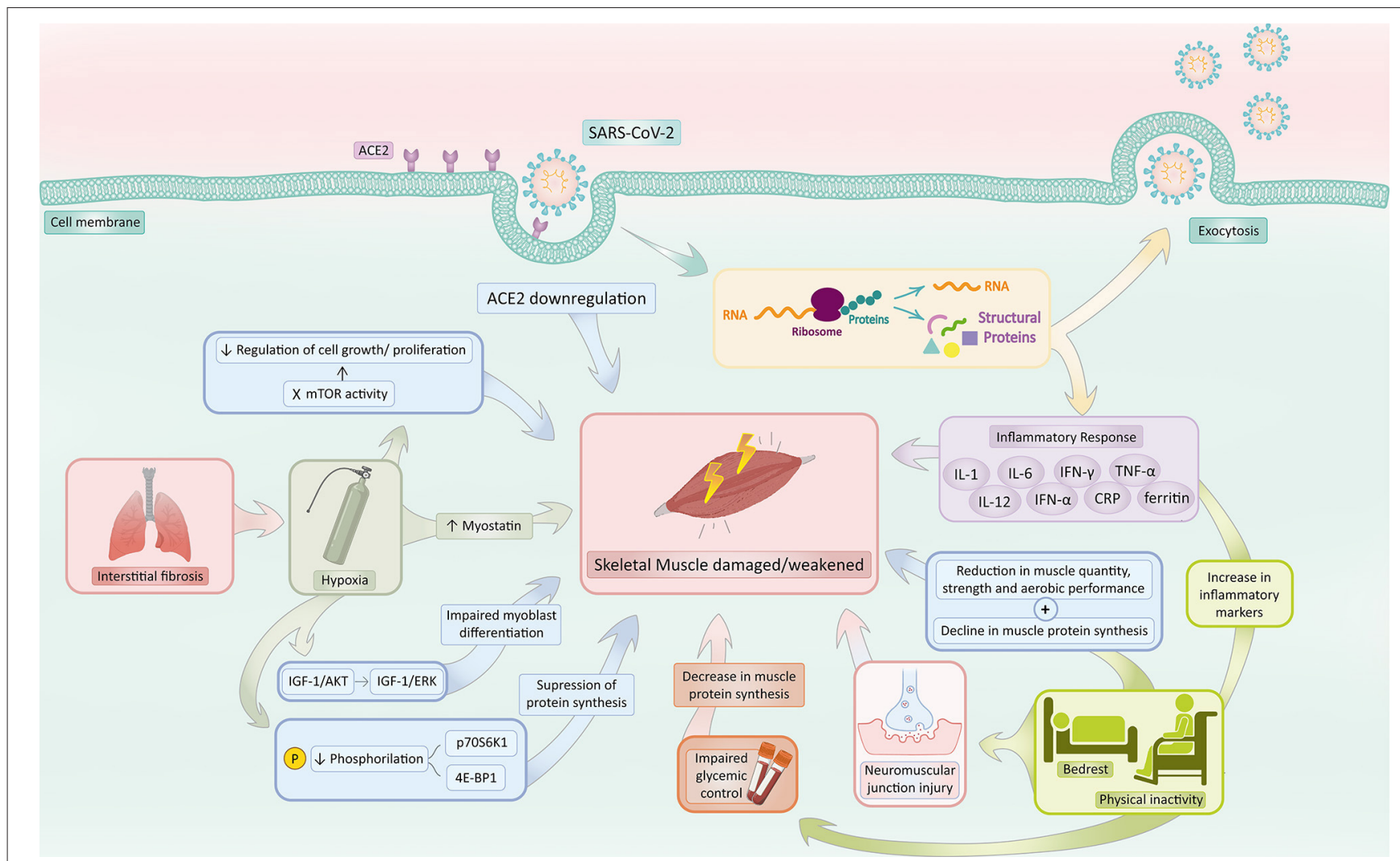

FIGURE 2 | COVID-19 associated sarcopenia mechanisms. SARS-CoV-2 infection activates a series of mechanisms responsible for increasing the risk of sarcopenia development. COVID-19 induces ACE2 downregulation and hinders the ACE2 protective effect, predisposing skeletal muscle to sarcopenia. The inflammatory response in response to infection, mainly characterized by the production of IL-1, IL-6, IFN- $\gamma, \mathrm{TNF}-\alpha, \mathrm{IL}-12$, IFN- $\alpha$, CRP, and Ferritin, prompts muscle catabolism, reducing muscle protein synthesis and increasing its susceptibility to damage and death. Bedrest and physical inactivity in the context of patients with COVID-19 not only increases several inflammatory biomarkers (such as TNF- $\alpha$, CRP, and IL-6) but also reduces muscle quantity, strength, anaerobic performance, and protein synthesis. Additionally, the inactivity state impairs glycemic control, which also contributes to a decrease in muscle protein synthesis and damages neuromuscular junctions. Interstitial pneumonia secondary to COVID-19 commonly triggers a state of hypoxia, which accounts for (1) a decrease in phosphorylation of p70S6K1 and 4E-BP1, (2) a switch from the IGF-1/Akt to IGF-1/ERK signaling pathway, (3) an increase in myostatin levels and (4) an inhibition of mTOR. The decrease in phosphorylation of p70S6K1 and 4E-BP1 suppresses protein synthesis. The switch from the IGF-1/Akt to IGF-1/ERK signaling pathway impairs myoblast differentiation. Elevated levels of myostatin activate catabolism and negatively regulate muscle growth. Inhibition of mTOR activity hampers the regulation of cell growth and proliferation, which augments the risk of damage within the skeletal muscle. Hypoxia, thus, makes the musculoskeletal system susceptible to sarcopenia. Created with adobe.com/illustrator.

elevated metabolic stress and muscle catabolism (56) (Figure 2), along with other symptoms, such as fever, cough, fatigue, headache, hemoptysis, and diarrhea (57).

As COVID-19 associated inflammation progresses, a process of systemic inflammation sets in, causing more severe damage to the organism (58). Concerning the inflammatory response in the disease, special attention has been given to the production of proinflammatory cytokines, mainly TNF- $\alpha$, IL-1, IL-6, and CRP, one of the main acute phase reactants. Ferritin, another acute phase reactant, has also been reported to be elevated in infected patients (57).

TNF- $\alpha$, for instance, negatively affects muscle protein synthesis (Figure 2), as it modifies Eukaryotic translation initiation factor $4 \mathrm{E}$ (eIF-4E) availability, which results in a reduction translational efficiency of Messenger Ribonucleic Acid (mRNA). The consequence of this process is the emergence of an anabolic resistance state, which demands a higher protein absorption to prompt muscle protein synthesis (59). Skeletal Muscle resistance to anabolic stimuli is a marker of muscle impairment in chronic degenerative and traumatic skeletal muscle diseases $(60,61)$.

Ferritin, an acute phase reactant also elevated in COVID19, has also been indicated as a compound that interacts with the production of energy in mitochondria, enhancing anaerobic metabolism as opposed to aerobic metabolism, which intensifies ROS generation and increases the susceptibility of cells to damage and death (Figure 2) (8).

The generally high level of inflammation experienced by patients infected by SARS-CoV-2 also makes the human body intensely vulnerable to multi-organ damage, a process hallmarked by endothelial harm and a predisposition to thrombosis, which greatly affects the musculoskeletal system (Figure 2) (8). 
In summary, it is highly likely that inflammation triggered by SARS-CoV-2 infection acutely impacts skeletal muscle physiology and function (Figure 2) (8).

\section{Bedrest and Physical Activity}

The extensive morbidity associated with COVID-19 may also predispose those affected to sarcopenia. Patients that experience the disease undergo prolonged periods of bed-rest as well as diminished physical activity and prevention of mobilization outside of ward areas or side rooms inside some hospitals (59). It is also important to note that immobilization due to COVID-19 hospitalization has been reported as more severe in comparison to other conditions such as limb fracture and severe pneumonia. As a consequence, these individuals face not only a reduction in muscle quantity, strength, and aerobic performance but also declines in muscle protein synthesis due to a modified expression of ubiquitin ligases (MuRF-1 and MAFbx) (Figure 2) (59).

It has been determined that patients hospitalized with COVID-19 experience rapid and dramatic muscle loss. Within the first 7 days of hospitalization, patients can experience a median decrease of $18.5 \%$ in the area of the rectus femoris muscle (8). Furthermore, chronic inactivity stimulates denervation of muscle fibers and neuromuscular junction (NMJ) injury, which has been demonstrated by an increment in NCAM (neural cell adhesion molecule)-positive muscle fibers in three separate bedrest studies lasting 3,10, and 15 days. As a glycoprotein usually expressed only in embryogenesis, hence absent in adult muscle, an increase of this protein in adult muscle indicates a denervation or reinnervation process in progress (Figure 2) (62).

Length of hospital stay and the severity of a patient's COVID-19 disease state are, therefore, intrinsically linked, as demonstrated by a translation of the GLISTEN study (63) to COVID-19, which reported that 11 days of COVID-19 hospitalization was associated with a $38.4 \%$ unadjusted increase in the risk of sarcopenia (8).

COVID-19-related social distancing measures and lock-down and have also contributed to the extensive inactivity that individuals have been recently facing. The Effects of home Confinement on multiple Lifestyle Behaviors during the COVID19 outbreak (ECLB-COVID19), a large electronic survey that was applied around the world and investigated the effects of lock-down measures during the first wave of COVID-19 in 1,047 people, detected a decrease in physical activity by and an increase in sitting time from 5 to $8 \mathrm{~h}$ per day (8). The inactivity style may predispose individuals to a decrease in insulin sensitivity and an increase in visceral fat, as reported in a study on healthy young men who performed little physical activity (29). These individuals have their normal metabolic arrangement unstabilized and, as a consequence, a reduction in insulin-provoked muscle Akt phosphorylation and in muscle protein synthesis ensues (Figure 2). Additionally, studies have shown that diminishing physical activity is associated with an elevation in inflammatory markers, mainly TNF- $\alpha$, CRP, and IL-6 (Figure 2) (29). In summary, it has been demonstrated that acute physical inactivity holds an intrinsic correlation with (1) impaired glycemic control, which reduces insulin-provoked muscle Akt phosphorylation, (3) inflammation augmentation, which predisposes the musculoskeletal system to intense damage (64) and (4) reduced muscle protein synthesis, as shown in Figure 2 (29).

\section{Pulmonary Involvement of COVID-19 on the Development of Sarcopenia}

It has been reported that SARS-CoV-2 begins its infection in the respiratory tissue. As a high-ACE2 and TMPRSS2-expression tissue, viral invasion progresses swiftly, which commonly causes viral interstitial pneumonia correlated with hypoxia (8). Hypoxia, in turn, triggers a string of adaptive responses, the main of which is a down-regulation of processes that demand elevated energy consumption, such as protein synthesis. A suppression in protein synthesis by multiple mechanisms, therefore, occurs. Firstly, there is an inhibition of the mTOR activity: Regulated in development and DNA damage responses-1 (REDD1), a hypoxia-inducible factor-1 target gene, and the sensor of cellular energy balance AMPK acts upon the mammalian target of rapamycin complex 1 (mTORC1) signaling during hypoxic stress, inhibiting it through phosphorylation of tuberous suppressor complex 2 (TSC2) (65). mTOR is part of the phosphatidylinositol 3-kinase (PI3K) cell survival pathway, which controls nutrient availability, mitotic signaling as well as cellular energy and oxygen concentration; therefore, mTOR is essential for the regulation of cell growth and proliferation (66). Decreases in the phosphorylation of Ribosomal protein S6 kinase beta-1 (p70S6K1) and eIF4E-binding protein 1 (4E-BP1) also occur, which reduces mRNA translation activity and inhibits protein synthesis - thus, impairing muscle development (65).

Hypoxia is also associated with higher levels of myostatin (8), an endogenous component of catabolic pathways in muscle cells and a negative regulator of muscle growth (67). Thus, greater concentrations of myostatin are associated with muscle degradation. Furthermore, hypoxia has been related to a switch from the IGF-1/Akt to IGF-1/ERK signaling pathway, which stimulates myoblast proliferation over differentiation, though myogenesis is still present (8). Observational studies with individuals exposed to high altitude hypoxia in mountaineering expeditions have also detected a reduction in muscle mass (68) and muscle fiber size, independently of physical activity levels (69), which confirms the relationship between hypoxia and skeletal muscle impairment.

In conclusion, it is possible to state that COVID-19 predisposes individuals to sarcopenia in multiple ways. The cytokine storm, physical immobilization, and hypoxia commonly present in SARS-CoV-2 infection are the key mechanisms that justify this predisposition. However, further studies are still required not only to confirm this hypothesis but also to investigate uncovered processes possibly contributing to sarcopenia in COVID-19.

\section{Cachexia}

Cachexia is a complex metabolic syndrome characterized by loss of muscle and associated with underlying illness (70). It is diagnosed upon clinically significant weight loss (71). In COVID-19, cachexia is diagnosed when there is $\geq 5 \%$ weight loss, functional status is impaired, and metabolic derangement (e.g., 
inflammation) can be documented. Other important factors that allow identification of the disease are: anorexia, low albumin, inflammation and increased muscle protein breakdown (72). There have been a few reports of cachexia secondary to COVID19 , particularly in cases of prolonged illness, which highlights the importance of studying the condition and its interrelation with SARS-CoV-2 infection (71).

Weight loss in COVID-19 is mediated by different mechanisms. First, the expression of acute-phase inflammatory proteins such as fibroblast growth factor, TNF $\alpha$, ferritin, CRP, IL-factors, interferon- $\gamma$, Nuclear factor kappa-light-chainenhancer of activated B cells (NF-kB), disturb tissue homeostasis, leading to dysregulation of metabolism and proteolysis (73). Second, there is the malnutrition commonly seen in patients with COVID-19. Appetite loss, ageusia, fever, and sedation in SARS-CoV-2 infection are the main factors contributing to malnutrition development (71). Along with that, the potential of SARS-CoV-2 to attack the mucosal epithelium in the gastrointestinal system is also an important element that explains malnutrition in COVID-19 (74). Thirdly, immobilization amid COVID-19 might also be associated with muscle wasting and weight loss (71). The elevated administration of sedatives and opioids aimed at facilitating mechanical ventilation in patients infected by SARS-CoV-2 can also play a role in weight loss and cachexia predisposition. Taking this all into consideration, a catabolic overdrive state ensues, triggering progressive weight loss in COVID-19 (71). Therefore, it is possible that patients that experience COVID-19 are at high risk of developing cachexia, which highly predisposes individuals to mortality and disability. There are still not enough studies that determine the exact relationship between cachexia and COVID-19. This dearth hampers differentiation between both clinical conditions and thus, adequate treatment of them both. In view of this, it is of extreme importance that deeper studies on the relation between cachexia and COVID-19 be developed.

\section{Myalgia}

Myalgia is one of the most common symptoms of COVID19, along with fever, cough, and sore throat. Prevalence of the condition amid SARS-CoV-2 infection, identified in a metaanalysis of clinical characteristics was 35.8\% (75). Another study, aimed at investigating the olfactory and gustatory function in patients experiencing COVID-19 found that more than 50\% of them had myalgia (76). Myalgia is a very common and non-specific symptom, generally defined as muscular pain (77). Muscle-related pain, in turn, is usually associated with a local hypersensitivity (hyperalgesia) to mechanical stimuli (78).

Myalgia usually presents due to generalized inflammation and cytokine response (79). The condition is commonly mediated by IL-6, whose upregulation triggers muscle and joint pain through activation of peripheral nociceptors (80). It was demonstrated in animal models that IL-6 induced hyperalgesia is probably mediated by an increase in pro-inflammatory cytokine production (mainly IL-1ß and $\mathrm{TNF} \alpha$ ), resident cell activation, polymorphonuclear cell infiltration, prostanoids and sympathomimetic amines release and activation of different intracellular signaling pathways, namely PLA2, PLC-PKC, PKA,
PI3K, and MAPKs (78). Of note, IL-6 has been shown not only to elicit acute muscle pain but also to evoke chronic muscle pain, which indicates that it plays an important role both in acute and chronic muscle pain (78).

It has been suggested that myalgia in SARS-CoV-2 infected patients reflects the generalized inflammatory state and the cytokine storm generated in the disease (80). Considering that COVID-19's cytokine storm presents with an elevation of IL6, TNF-a, and IL-1ß and that pathophysiology of myalgia also involves these cytokines, it seems reasonable to associate SARS$\mathrm{CoV}-2$ infection with myalgia. It has also been proposed that muscle involvement in COVID-19 may stem from deoxygenation of the musculoskeletal system: surplus cell damage in SARSCoV-1-infection may increase lactate levels in the human body. Hyperlactemia, in turn, impairs (1) aerobic respiration and ATP synthesis and (3) oxygen-carrying capacity of erythrocytes predisposing tissues to hypoxia. Reduced ATP production leads to pain and fatigue. Decreased oxygen transportation may induce an ischemic state in muscles during COVID-19 infection (81). Hypoxic ischemia elicits a state of increase in growth factors, cytokine levels, and microvascular alterations that may induce overexpression of these substances' receptors in the dorsal root ganglion, generating pain (82). The exact mechanisms of myalgia, despite a few hypotheses that have been published, are still not completely understood. Thus, in view of the considerable presence of myalgia as a clinical manifestation of COVID-19, further investigation of the musculoskeletal condition and its association with SARS-CoV-2 is yet needed.

\section{Myositis and Subtypes}

There have been a few case reports indicating myositis as a manifestation of COVID-19. To date, $\sim 23$ cases related to SARSCoV-2 infection have been described (83). The prevalence of the condition varies between 11 and 50\% among scientific studies (84). It has been determined clinically that acute viral myositis has the potential of presenting as a sole manifestation of COVID19 infection without respiratory symptoms (85), which indicates the importance of studying the disease.

Myositis secondary to COVID-19 may manifest in multiple forms, which range from muscle weakness to typical dermatomyositis identified mostly by classic rashes, or sheer back pain (83).

The first MRI-proven case of myositis induced by COVID19 was reported in April 2020 in France (84). In this patient, autoimmune myositis was hypothesized due to the demonstrated association of myositis followed by interstitial pneumonitis in a COVID-19 patient, even though further immunological tests searching for any forms of myositis were negative. This has led to the conclusion that the association between muscle inflammation and interstitial pneumonia can be found in either COVID-19 or autoimmune myositis (84). Dermatomyositis, for instance, has been indicated as a potential trigger of interstitial lung disease, especially in anti-MDA5 (anti-melanoma differentiationassociated gene 5) antibody-positive patients, which are at higher risk for developing interstitial lung disease (83). This makes it difficult to differentiate dermatomyositis from interstitial lung 
disease and associate it with COVID-19 acute respiratory distress syndrome in SARS-CoV-2 infected patients (86).

On the other hand, it has also been suggested that viral infections can spur the development of autoimmune disorders such as myositis through myositis-specific antibodies. Along with this finding, a steep increase in dermatomyositis cases between April and August 2020, a period concurrent with the COVID-19 pandemic, has been reported in the city of Mumbai, India (86). With a few other studies outlining the interrelation between dermatomyositis and COVID-19, it has been stated that dermatomyositis might be another musculoskeletal manifestation of SARS-CoV-2 infection (83).

Dermatomyositis is commonly presented as typical raches, such as malar erythema, heliotrope with periorbital edema, or diffuse facial rashes associated with symmetric and proximal muscle weakness. Diagnosis of dermatomyositis normally includes the identification of myositis-specific autoantibodies, such as anti-Mu2, anti-MDA5, anti-SAE1 (anti-small ubiquitin-like modifier-1 activating enzyme), or anti-nuclear autoantibodies (87).

A series of case reports in Mumbai, India indicated that MDA5 may drive the production of great amounts of type I interferons, which contributes to the innate immune response against viruses (86). As a viral sensor, MDA-5 is activated by viral RNA.

It is known that immune response against coronavirus usually encompasses IFN induced with helicase $\mathrm{C}$ domain protein 1 (IFIH1) production, whose gene is a target of antiMDA5 antibodies, which would contribute to an increase in MDA-5 production during viral infection, intensifying immune responses against viruses. Experts around the world have been examining COVID-19, for instance, as a possible human model of anti-MDA5 Idiopathic inflammatory myopathy (IIM), which might enhance COVID-19 treatment development: high-dose corticosteroids, human immunoglobulins, Janus kinase (JAK) inhibitors, and $\mathrm{T}$ cell modulators currently in trials and IL6 inhibitors (e.g., tocilizumab), anti-GM-CSF (gimsilumab), IL-1 inhibitors (e.g., anakinra), and anti-IFN $\gamma$ agents (e.g., emapalumab) could, thus, be considered as a potential treatment of COVID-19 (88).

As indicated by the series of case reports in Mumbai, India, MDA-5 may drive the production of great amounts of type I interferons, which not only contributes to the innate immune response against viruses (86) but also accounts for autoimmune triggers in dermatomyositis (89). Moreover, an increase in type I interferons is also seen in coronavirus infections, due to the fact that IFIH1 augments the production of cytokines such as IFN- $\gamma$, IL-1 $\beta$, TNF- $\alpha$, IL-6, and IL-18 (86), which would contribute to autoimmune disease emergence. This was recently demonstrated in dermatomyositis patients in 2020 which identified six distinct epitopes with high sequence identity to the human SARS-CoV-2 virus. Three of the linear epitopes of six amino acid lengths were indicated as highly specific for SARS-CoV-2 (87). Thus, it is possible to assume that SARSCoV-2 infection may contribute to musculoskeletal autoimmune disease development.

Furthermore, a significant expression of MHC class I antigens on the sarcolemma of COVID-19-patients in the early phase of the disease has been detected. Additionally, an upregulation of MHC class II on myofibers antigens in later stages of the viral infection has also been identified in these patients, which reinforces skeletal muscle's involvement in the immune response against SARS-CoV-2 (90).

\section{Rhabdomyolysis}

Rhabdomyolysis has been indicated by the scientific literature as a possible manifestation of COVID-19. The condition is a syndrome that stems from skeletal muscle damage, which triggers the release of intracellular muscle proteins and enzymes into the bloodstream (91), or from a failure of energy production, which increases intracellular calcium, causing cellular lysis (92). Symptoms of rhabdomyolysis encompass myalgia, muscle weakness, fatigue, and darkcolored urine. Elevated concentrations of creatine kinase, lactate dehydrogenase, transaminases, and myoglobin levels are commonly detected in the syndrome $(91,93)$. Rhabdomyolysis can be caused by trauma, exertion, medications and drugs, myopathies and metabolic syndromes, and infections, including infectious myositis (92).

During the COVID-19 pandemic, diagnosis of rhabdomyolysis has been hampered mainly because both rhabdomyolysis and COVID-19 are characterized by fatigue, myalgia, and elevated levels of liver enzymes and lactate dehydrogenase. To date, only two cases of rhabdomyolysis secondary to COVID-19 have been reported. Thus, it is of critical importance to investigate the inter-relation between rhabdomyolysis and SARS-CoV-2 infection so as to differentiate the conditions and treat them both adequately. A recent case report of COVID-19 induced rhabdomyolysis has demonstrated that creatine kinase levels $>5$ times the normal value in patients hospitalized with COVID-19 might be indicative of rhabdomyolysis, which would contribute to medical professionals failing to identify and diagnose rhabdomyolysis when COVID-19 is present (91).

Mechanisms of rhabdomyolysis induced by acute viral infection remain unclear. They may be associated with myotoxic cytokines that have the potential to cause immune-mediated injury and direct viral invasion damage. It has been indicated that a general infection causing rhabdomyolysis might be related to direct injury established by the pathogen or an exacerbated inflammatory response (93). Myotoxic substances as a treatment for SARS-CoV-2 infection may also induce side effects that are correlated to rhabdomyolysis (93). Immune cross-reactivity between antigens and myocytes, deposition of antigen-antibody complexes, and viral transformation of host cells and host proteins might also prompt an exaggerated immune response and muscle damage associated with rhabdomyolysis (92).

Rhabdomyolysis triggered by SARS-CoV-2 infection is of critical significance. The debilitating effects of the condition on patients, especially those that are already experiencing COVID19 and its associated morbidity, pose a serious threat to these individuals' lives. Therefore, in order to enhance patient outlook, further studies on the inter-relation between the two conditions are absolutely required. 


\section{Skeletal Muscle Atrophy}

Many patients that experience COVID-19 are required to undergo invasive mechanical ventilation to avoid a complete collapse in gas exchange, respiratory muscle fatigue, organ failure, and, ultimately, death. Mechanical ventilation associated with critical SARS-CoV-2 infection plays a relevant role in the deterioration of respiratory muscle structure and function, especially the diaphragm muscle, the main inspiratory muscle (11).

Mechanical ventilation induces a process of partial or complete unloading of respiratory muscles' activity, which leads to weakness, and silences the respiratory control centers in the brain stem (11). Regarding the diaphragm muscle, its inactivity during mechanical breathing is the main contributor to weakness (94), characterized by reduced motion, thinning, and decreased capacity to generate pressures in response to the phrenic nerves' stimulus. Inactivity of this muscle has also been associated with the abundant generation of ROS, apoptosis activation via caspase- 3 expression, and upregulation of mRNA coding for ligands that are associated with the proteolytic ubiquitin-proteasome pathway (95). Inflammatory mediators play a causative role in diaphragm dysfunction, due to the activation of proteolytic pathways and an increased amount of neutrophils and macrophages (11).

These findings are of critical importance to severely ill SARSCoV-2 infected patients since constantly evaluating mechanical ventilation time could potentially contribute to reducing COVID-19's detrimental effects on patients. Decreasing the time to which patients are exposed to mechanical ventilation may limit the destructive potential of the process on respiratory muscles and functional status (11).

\section{Musculoskeletal Neuromuscular Complications Due to COVID-19 Peripheral Neuropathy}

Peripheral neuropathy refers to a group of disorders that affect the peripheral nervous system (96). Patients normally present with sensory abnormalities and autonomic dysfunction. The condition is usually associated with increased morbidity, especially due to the presence of neuropathic pain, weakness, falls, and disability in individuals affected by it. Patients usually undergo sensory abnormalities, and autonomic dysfunction (97).

Peripheral neuropathy and COVID-19 seem to be correlated, due to the fact that there has been a progressive amount of case reports of peripheral neuropathy in SARS-CoV-2 infected patients $(98,99)$. The condition has been reported to stem from a few conditions, mainly compressive neuropathies, symmetric polyneuropathy, mixed central and peripheral nervous system disorders, and systemic effects from critical illness neuropathy (100).

The influence of SARS-CoV-2 on the nervous system depends upon virus entrance into the system. Although the exact mechanism of entry into the central nervous system (CNS) is still undetermined, studies have suggested that virus routes may include retrograde neuronal transport across infected neurons, entry via the olfactory nerve's neuroepithelium (101), entry via the sensory fibers of the glossopharyngeal, entry via peripheral nerve (102), infection of the white blood cell or vascular endothelium travel across the blood-brain barrier (100, 103). It was also hypothesized that the virus might have direct access to the CNS, due to the fact that there have been two cases reporting SARS-CoV-2 in the cerebrospinal fluid (CSF) (104). This would be explained by the presence of ACE2 on neurons and glial cells in the CNS (105). Additionally, it has been indicated that SARSCoV-2's typical cytokine storm may play a role in neuropathy development (99). Additionally, side effects of drugs used to treat COVID-19 symptoms and compression of peripheral nerves due to prolonged ICU-bedding in patients infected by the virus might also contribute to peripheral neuropathy in the setting of COVID-19 (12).

Peripheral neuropathy in patients infected by SARS-CoV-2 has been a challenge both to the healthcare professionals and to the patients themselves. Uncertainty regarding the relationship between the diseases has been hampering the ability of these professionals to generate better medical end results for the patients. Thus, it is of extreme importance to investigate the conditions in a more thorough manner, especially through clinical studies, which would contribute not only to improved clinical outcomes but also to enhanced treatment.

\section{Guillain-Barré Syndrome and Subtypes}

Guillain-Barré Syndrome (GBS) is an autoimmune neurologic disease comprised of a spectrum of polyneuropathies (102) characterized by ascending muscle weakness associated with decreased or absent deep tendon reflexes, mild to moderate sensory loss, occasional cranial nerve involvement, and radicular or muscle pain. The syndrome is usually demyelinating, but it can also involve primary axonal injury [sensory axonal neuropathy (AMSAN) and acute motor or acute motor axonal neuropathy (AMAN)] (106). The most common subtype of the disease is the acute inflammatory demyelinating polyneuropathy (AIDP), AMAN, and the Miller Fisher syndrome (MFS) characterized by acute ophthalmoplegia, gait ataxia, and areflexia (102).

The condition is normally triggered by viral infections, which is supported by the fact that in $70 \%$ of cases, neurologic symptoms' advent may depend on the precedent occurrence of viral illness (106). General coronaviruses, for instance, already had their involvement with neurological disease demonstrated by scientific literature. There have been recent reports of GBS possibly triggered and even caused by COVID-19 (101). Numerous cases of the neurological syndrome post-COVID19 have been reported to follow either a para-infectious or a post-infectious pattern (107), para-infectious being more common (108).

SARS-CoV-2 molecular mechanisms involved in COVID19 nerve damage are still not clear, even though there are a few hypotheses that have been proposed, as previously stated herein. Particularly in GBS, SARS-CoV-2 infection could drive the production of antibodies against specific antigens associated with the neurological disease (109) (Figure 1). It is also likely that the cytokine storm triggered by COVID-19 takes part in the development of GBS in SARS-CoV-2 infected patients, as it has been reported that cerebrospinal fluid of patients with GBS is 
characterized by elevated IFN- $\gamma$ and their serum, characterized by elevated TNF- $\alpha$, which are cytokines that are also peaked in the setting of COVID-19 (108). Previous systematic reviews of GBSs cases in the context of COVID-19 have demonstrated that SARS-CoV-2 infection symptoms usually precede GBS manifestations at a median interval of 14 days. This 2-week interval between both conditions coincides with the second phase of COVID-19, marked by the cytokine storm, which would reinforce the participation of COVID-19 cytokines in the pathogenesis of GBS in SARS-CoV-2 infected patients. In this phase, critically ill patients suffering from COVID-19 may manifest GBS in a masquerade form as a mere critical illness polyneuropathy. Thus, difficulty in weaning from mechanical ventilation may be a consequence of GBS (110).

Apart from that, it has been suggested that SARS-CoV-2 entrance on cells depends upon $S$ protein binding not only to ACE2 receptor but also to glycoproteins containing sialicacid and cell surface gangliosides, which would interestingly increase viral transmissibility (111). Gangliosides are sialylated glycosphingolipids located profusely in several nervous tissues. Antiganglioside antibodies commonly develop post-infection (typical GBS course in the classical form of the disease) (108) since gangliosides and infectious agents share epitopes, which leads to a molecular mimicry phenomenon: binding of the antibody to nerves, which causes impaired conduction of impulses and axonal degeneration (108). That is, the antibodies formed against the viral glycoproteins act upon glycoconjugates on the neural tissue, mainly myelin, and axon of peripheral nerves, impairing it (75).

Copious gangliosides, mainly those that contain a disialosyl moiety (GQ1b, GT1b, and GD1b, for example) or 2 gangliosides that share epitopes with GM2, or a combination of GM1 and GM2, GD1b and GM1, can work as antigens in patients with neuropathies (112). When IgM recognizes the Gal (pl3) GalNAc moiety of GM1, which is found on the surface of motor neurons, a motor neuropathy typically occurs, and when it recognizes epitopes that contain disialosyl groups of GDlb (located on the dorsal root of ganglionic neurons), patients present with sensory ataxic neuropathy (112). SARSCoV-2S protein probably interacts with the GalNAc residue of GM1 and dimers of ganglioside for anchoring to cell surface gangliosides. This process is likely to generate crossreactivity between epitopes within SARS-CoV-2 gangliosides that bear $S$ protein and surface peripheral nerve glycolipids (102), which act as a mechanism in SARS-CoV-2 triggered autoimmune GBS. In accordance with that is the report of numerous GBS variants in SARS-CoV-2 in the scientific literature (106).

As a rare but potentially fatal neurological condition, primarily due to swiftly progressive weakness of limb, bulbar, and respiratory muscles (108), special attention should be given to GBS development in the setting of COVID-19. Early diagnosis and management can improve clinical outcomes. Considering the yet unclear mechanisms of GBS emergence and SARS-CoV-2 infection, more extensive studies are still needed (109).

\section{MITIGATION OF SARS-COV-2 IMPACT ON SKELETAL MUSCLE}

The detrimental effects of COVID-19 on skeletal muscle, herein previously outlined, are characterized by a variety of causes, especially inflammation. Because COVID-19 recovery poses a multidimensional challenge, different aspects of the disease should be analyzed: for instance, from pre-infection up to moderate illness, strategies that address viral replication and immune system fortification should be examined, while in more severe cases, anti-inflammatory strategies need to be the focus (113). In order to mitigate the burden caused by SARS-CoV2 infection on skeletal muscle, a few of those strategies should be mentioned.

Initially, studies have indicated some diet alterations that might act in favor of the immune system. Meals filled with plants rich in antioxidants, for instance, may improve the immune system defenses against viral infections $(114,115)$ (Figure 3): blueberry, for example, has been shown to increase the amount of NK cells and anti-inflammatory cytokines, upon acute ingestion (116). In contrast with that, processed oils (as opposed to short-chain fatty acids), for instance, shall be avoided, due to the demonstrated enhancement of a more proinflammatory state when ingested (117). Avoiding alcohol should also be recommended since a few studies have demonstrated that it jeopardizes not only the function of key immune cells, such as macrophages and neutrophils in the alveoli, but also the barrier structure of lower airway epithelia.

Besides diet modifications, moderate sunlight exposure also seems to play a role in immunity enhancement: the production of vitamin $\mathrm{D}$ in the skin, stimulated by sunlight, may enhance the function of T cells (118-120) (Figure 3).

Exercise is another practice that acts in favor of the immune system, playing a pivotal role in boosting it (121). Moderate physical activity is associated with a higher intensity of macrophage anti-pathogenic activity and elevations in antiinflammatory cytokines, which would contribute to alleviating the effects of pathogens on the organism (122). During exercise, inflammatory response and stress hormones are normally decreased whereas lymphocytes, NK cells, immature B cells, monocytes (123) and naive T cells (123) are increased, which, on the whole, determines an improvement in immunovigilance (123). The modulatory effect of physical exercise has also been demonstrated in a few studies by an increase in myokines, such as myostatin, IL-6, IL-10 and leukemia inhibiting factor (124) (Figure 3). Importantly, even though IL-6 participates intensely in acute inflammation, the cytokine has also been shown to exert anti-inflammatory effects (125). Studies regarding aerobic exercise detected diminished levels of senescent/exhausted CD4 and CD8 T cells (126) and reduced immunosenescence (127), which is positively associated with the quality and quantity of antibodies against SARS-CoV-2 $(125,128)$. Besides that, during physical activity, enhanced expression of the antioxidant Extracellular Superoxide Dismutase enzyme (EcSOD) has also been detected. EcSOD plays an important role in oxidative stress 


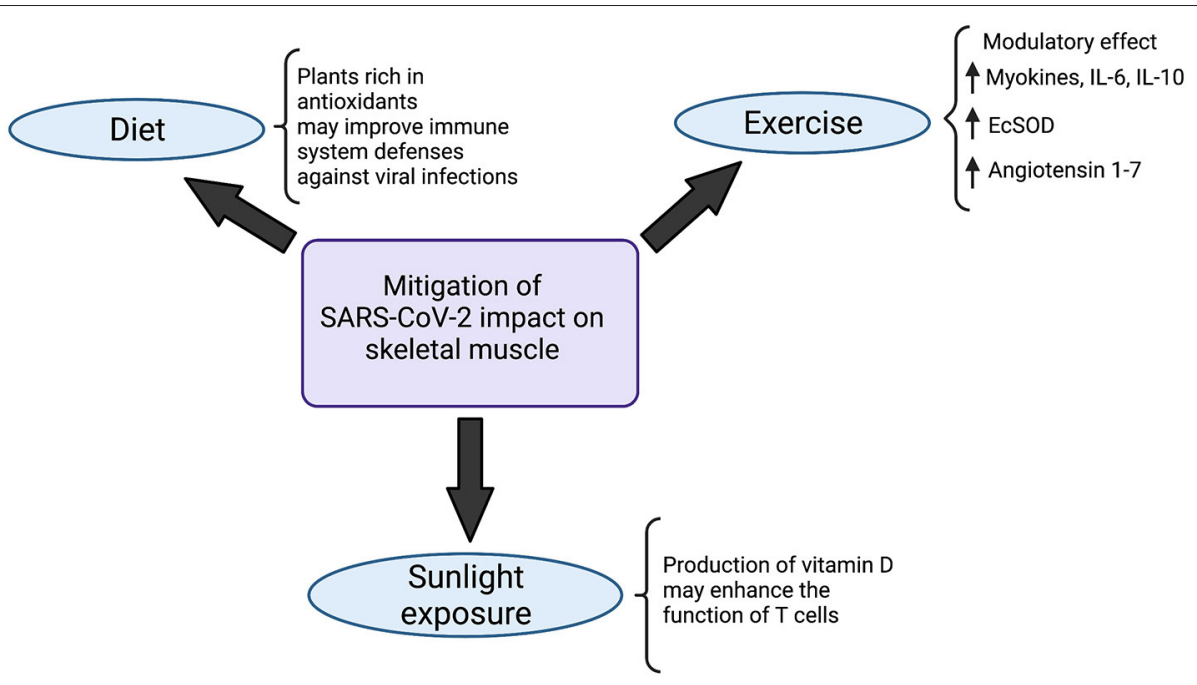

FIGURE 3 | Strategies to mitigate SARS-CoV-2 impact on the musculoskeletal system. Diet modifications, sunlight exposure and exercise have been indicated in the literature as potential strategies to minimize the impacts of SARS-CoV-2 on skeletal muscle. Meals rich in antioxidant plants likely boost defenses of the immune system, improving viral infections combat. At the same time, the production of vitamin $\mathrm{D}$, triggered by exposure to sunlight, enhances the function of $\mathrm{T}$ cells. Physical activity, on the other hand, exerts a modulatory effect in the organism, mainly characterized by a state of increase in myokines, IL-6 and IL-10, which improves the body's immunovigilance. Augmented expression of antioxidant Extracellular Superoxide Dismutase enzyme (EcSOD) has also been detected during exercise, which contributes to both oxidative stress and tissue damage reduction. Angiotensin 1-7 also seems to be upregulated in the setting of physical activity, which plays a role in mitigating the deteriorating effects of SARS-CoV-2 in the organism. Created with Biorender.com.

and tissue damage reduction in the setting of COVID-19 (129) (Figure 3).

Additionally, an exchange of white blood cells between the tissues and the circulatory system takes place during regular exercise, which is responsible for reducing morbidity and mortality associated with acute respiratory illnesses and viral infections (130). Exercise, particularly the ones that overload the cardiorespiratory system, also generate a state of mobilization and redistribution of effector lymphocytes, which is mediated by catecholamines. These lymphocytes then migrate to structures such as the upper respiratory tract, lungs and intestines, where they recognize and combat pathogens, improving response against viruses (131). Studies that analyzed Influenza infection indicated that moderate exercise is an important factor in viral load and inflammatory response reduction (132) (Figure 3).

On top of that, exercise seems to prompt an upregulation of lung ACE receptor, which accounts for an increase in the production of angiotensin 1-7. Considering the protective effects of angiotensin 1-7 in the organism, it could be stated that exercise contributes to a mitigation of the harmful effects of SARS-CoV2 in the lungs (133). Considering that the respiratory tract is the source of entrance of the virus, reducing the effects of viral infection in the lungs could also exert a protective role on the rest of the organism (Figure 3).

Overall, good physical conditioning has been correlated with a reduction in risk of latent viral infections reactivation, characterizing a better immune system dynamic (131). Aerobic activity has been associated with a significant decrease in severity and incidence of symptoms of upper respiratory tract infections (URTI) (134).
Importantly, intense physical activity before or during an infection such as COVID-19 and influenza is not recommended, since it can precipitate severe disease $(123,135)$ due to the immunosuppression induced by Th2 anti-inflammatory cytokines aimed at reducing muscle tissue damage $(122,135)$. Therefore, intense exercise should be avoided until normalization of the symptoms and end of the disease (136). In conclusion, it is possible to state that as a potential enhancer of the immune system, physical exercise could be pointed as an important factor for protection against the deleterious effects of SARS-CoV-2 on the human body.

\section{BIOENGINEERING AND SKELETAL MUSCLE MODELS}

Given the current uncertainty that exists around the long-term impact of SARS-CoV-2 infection on skeletal muscle, there is a need to establish a body of research that directly interrogates muscle tissue dynamics during both SARS-CoV-2 infection and recovery. Traditionally, skeletal muscle biology is studied in 2D cell culture, animal models, or through direct sourcing via biopsies from healthy and diseased individuals. Though samples isolated from human subjects are ideal, ethical considerations and low availability of tissue limit the scope of studies able to be performed. Despite the fact that animal models have been frequently utilized, both replicability and translatability to human disease are relatively poor (137-139). 2D cell culture of immortalized muscle cell lines induced to myotubule differentiation through serum starvation is also commonly 
applied in rapid drug screening assays (140). However, despite the benefits of being able to control differentiation and precisely monitor cell microenvironment, the myotubules formed are developmentally immature with limited physiological relevance and thus the information gleaned is likewise limited in kind.

Physical features of stiff 2D culture plates have been found largely at fault for this functional immaturity, shortening culture duration and decreasing muscle-specific gene expression. In contrast, substrates with similar stiffness of $12-18 \mathrm{kPa}$ to that of native skeletal muscle tissue have demonstrated improved myotubule structure $(137,141)$. As a result, great strides have been made to create biomimetic 3D muscle culture to better study muscle dynamics in drug and pathology research in vitro. Compared to $2 \mathrm{D}$ muscle cell culture, $3 \mathrm{D}$ culture allows for increased myotube size, longer culture times, and protein content, and improved maturation of the key skeletal muscle gene myosin heavy chain (MHC) (142-144).

The field of bioengineering is continually playing a promising larger role in the study of muscle pathology and regenerative medicine on the preclinical level as 3D biomimetic cultures are being further refined. 3D cultures with the goal of studying muscle dynamics should use proper cells and signals within a matrix that (1) accurately replicates structure function and regenerative capacity of native structures, (2) represents the phenotype of the disease of interest, and (3) is able to be monitored by the most current functional and metabolic technologies $(137,145)$.

\section{Biomaterials for 3D Skeletal Muscle Modeling}

Biomaterials are material systems that have been engineered to direct the course of a diagnostic or therapeutic procedure by controlling interactions with components of living systems either alone or in part of a system (146). The term biomaterial is a broad classification of either naturally sourced or synthetically generated materials that have applications ranging from in vitro modeling to clinical tissue engineering systems for regenerative medicine.

Functional in vitro skeletal muscle models as summarized in Table 1 provide a biomimetic microenvironment with tissue-specific ECM qualities and mechanical and biochemical signals that promote accurate tissue function and rapid tissue maturation. Biomaterials utilized must be biocompatible, have high surface area for cell interaction and adhesion activity, provide mechanical integrity over both short and long terms, and must be diffusion capable to meet cellular nutrient and gas transport needs.

\section{Synthetic ECM}

The most up-front approach utilized in efforts to engineer and model skeletal muscle has been to synthetically generate ECM structures to better replicate muscle tissue microenvironments. A wide variety of biomaterials have been utilized as the basis for these structures, including both synthetically engineered and naturally derived material systems.

Synthetic materials have been frequently utilized for skeletal muscle regeneration, including polyethylene glycol (PEG), poly lactic-co-glycolic acid (PLGA), poly-l-lactic acid (PLLA), polyglycolic acid (PGA), their copolymers (PLLA/PLGA), and polycaprolactone (PCL) (147). Synthetic material systems have several advantages in their application, including overall replicability, physical property standardization, and the ability to be readily formulated into many different geometries and patterns. As a result, structural properties can be tuned with high precision to address case-specific needs (147). These characteristics have been able to enhance myoblast alignment and differentiation capabilities (148). Though synthetic materials have the potential of precise physical property tuning and are capable of cell supportive modifications, robust limitations to clinical application still exist-including their degradation products, suboptimal biocompatibility, and immunogenicity potential.

Biologically sourced material systems from plants and animals tend to display favorable biocompatibility and degradation byproduct profiles than their synthetic counterparts. Chitosan, silk fibroin, alginate, and agarose are all biologically derived and commonly applied in biotechnology industries (149-151). All of these compounds have been broadly applied in tissue engineering strategies because of endogenous bioactive properties that allow them to naturally link growth factors (147). For example, alginate hydrogels are able to assist in myoblast proliferation and maturation while also promoting the release of growth factors essential for muscle regeneration through polymer modification $(148,152-155)$.

Mammalian sourced material systems, such as collagen and fibrin, have the benefit of being naturally decorated with proteins and signaling molecules that muscle cells directly interact with. Collagen, type I collagen specifically, is the most abundant ECM protein in native skeletal muscle (137) and was also the first material system utilized to generate a 3D model of skeletal muscle in 1988-in which avian sourced myotubules were embedded into a type I collagen gel scaffold (143). 3D collagen scaffolds have also been shown to be supportive in rodent and human primary skeletal muscle myoblast culture applications and in the formation of engineered skeletal muscle tissue (156-158). Collagen scaffolds have demonstrated the ability to increase myotubular alignment and effectively stimulate growth (159161). Though it has been shown to be useful, type I collagen also has limitations in skeletal muscle engineering endeavors. Collagen is not easily remodeled, does not stimulate ECM secretion, in high concentrations has resulted in low contractile forces and has adverse effects on muscle cell maturation $(162,163)$. Thus, though collagen was very frequently utilized in early skeletal muscle tissue engineering endeavors, other material systems have since been identified that usurp these critical shortcomings.

Fibrin is core to the healing process in animals as the major structural component in the blood-clotting pathway. Once a blood clot forms, it is structurally replaced with secreted cellular ECM during the healing process (164). It is due to this endogenous remodeling capability that fibrin is commonly applied in skeletal muscle modeling and tissue engineering endeavors, as muscle cells are able to degrade and replace the base fibrin scaffold with naturally secreted ECM (165). 
TABLE 1 | Bioengineering skeletal muscle models.

\begin{tabular}{|c|c|c|}
\hline Model & Benefits & Limitations \\
\hline \multirow[t]{2}{*}{ Synthetic ECM } & $\begin{array}{l}\text { Chemically sourced } \\
\text { - High replicability } \\
\text { - Standardized physical properties of source material } \\
\text { - Ability to be formed into unique geometries } \\
\text { - Precise tuning of final structure mechanical properties } \\
\text { - Enhanced myoblast alignment and differentiation } \\
\text { - Ease of chemical modification }\end{array}$ & $\begin{array}{l}\text { Chemically sourced } \\
\text { - Potentially caustic degradation products } \\
\text { - Biocompatibility issues } \\
\text { - Immunogenicity }\end{array}$ \\
\hline & $\begin{array}{l}\text { Naturally sourced } \\
\text { - Generally biocompatible } \\
\text { - Safe degradation products } \\
\text { - Naturally have (or have the ability to) link growth factors } \\
\text { - Enhanced myotubular alignment } \\
\text { - Muscle cell growth stimulation }\end{array}$ & $\begin{array}{l}\text { Naturally sourced } \\
\text { - High prevalence of batch variability } \\
\text { - Mixed endogenous remodeling capabilities } \\
\text { - Native ECM secretion stimulation is highly dependent on the } \\
\text { material selected } \\
\text { - Low contractile forces } \\
\text { - Difficulty stimulating muscle cell maturation }\end{array}$ \\
\hline Decellularized tissue & $\begin{array}{l}\text { - Native tissue architecture is maintained (basement } \\
\text { membrane architecture, vascular networks) } \\
\text { - Endogenous bioactive molecules are present (growth } \\
\text { factors, glycosaminoglycans) } \\
\text { - Mechanical properties of source tissue are maintained } \\
\text { - Supports innervation }\end{array}$ & $\begin{array}{l}\text { - Size limitations } \\
\text { - Lack of homogeny in decellularization } \\
\text { - Volumetric limitations }\end{array}$ \\
\hline Scaffold free assembly and organoids & $\begin{array}{l}\text { - Capable of long-term cell culture } \\
\text { - Multi-lineage cell culture supportive } \\
\text { - Quantifiable means of determining muscle activity and } \\
\text { dynamics } \\
\text { - Able to recapitulate some specific physiological structures, } \\
\text { albeit on a smaller scale }\end{array}$ & $\begin{array}{l}\text { - Size limitations } \\
\text { - Long-term culture requirements } \\
\text { - Biological transport issues } \\
\text { - Scale-up feasibility }\end{array}$ \\
\hline Microfluidics and microchips & $\begin{array}{l}\text { - Precise control of culture microenvironment } \\
\text { - High throughput } \\
\text { - Utility in drug screening } \\
\text { - Capable of long-term cell culture } \\
\text { - Can stimulate skeletal muscle differentiation and maturation } \\
\text { - Quantifiable means of determining muscle activity and } \\
\text { - dynamics } \\
\text { - Multi-lineage cell culture supportive }\end{array}$ & $\begin{array}{l}\text { - Lack of 3D tissue architecture } \\
\text { - Limited geometries } \\
\text { - Highly complex assembly } \\
\text { - Scale-up feasibility }\end{array}$ \\
\hline
\end{tabular}

The benefits and limitations associated with bioengineering skeletal muscle modeling systems.

Additionally, fibrin has a stiffness similar to that of native skeletal muscle structures, unlike type I collagen, which is far stiffer (165-167). Beyond physical property similarities, fibrin also has demonstrated the ability to promote angiogenic and neuronal activity-therefore fibrin has great promise in generating more realistic tissue microsystems to better recapitulate the in vivo environment $(168,169)$. Like any other naturally sourced system, batch-to-batch variability is still a challenge, however, this can be mitigated through testing and controls (144).

\section{Decellularized Tissues}

Compared to scaffolds consisting of one or two biopolymers engineered to mimic native ECM structures, there is also the option to apply native ECM structures directly. Compared to engineered scaffolds, decellularized scaffolds maintain native microstructures, bioactive molecules, and vascular networks while similarly maintaining the mechanical properties of the tissues from which they are sourced $(170,171)$. As a result of having native skeletal muscle growth factors, basement membrane structural proteins, and glycosaminoglycans, myogenic cell proliferation is supportive and in vivo remodeling in response to seeded decellularized scaffold application is feasible (171). Biologic scaffolds have also demonstrated the ability to support skeletal muscle reconstruction through significant vascularization and innervation and the formation of both type I and type II muscle fibers (172). Even greater regenerative capacity is seen with the uniaxial stretching (173) and the application of these decellularized tissues with stem or progenitor cells (174). However, there exist several limitations in the execution of this technology-including the lack of homogeny in decellularization in larger, thicker tissue samples such as skeletal muscle and critical volumetric limitations in their application in general (174). Despite these limitations, greater strides in perfusion decellularization techniques and co-application with cell therapies have made volumetric muscle loss repair more translationally feasible (175).

\section{Scaffold-Free Assembly and Organoids}

Self-assembled 3D tissues can also be formed through endogenous ECM secretions without the utilization of material systems. Self-assembled skeletal muscle tissue has been assembled through a variety of means, including the utilization 
of non-cell supportive membranes (176), micropatterning (177-180), and monolayer layering (181-183) in either pure or co-culture with fibroblasts or other viable cell lineages. Organoids have the potential of generating microscale systems for monitoring skeletal muscle activity over longer terms that can span months (184). In addition to skeletal muscle cells, skeletal muscle organoids can contain cells of different lineages for monitoring specific physiological structures, such as neuromuscular junctions (184). Recent advancements in the creation of vascularized skeletal muscle organoids have been providing a possible solution to current organoid size limitations (185). In addition, fully human, multilineage skeletal muscle organoid models that contain all lineages essential to skeletal muscle, including endothelial cells, pericytes, and motor neurons have also been recently successfully generated with the use of iPSCs (186). Skeletal muscle organoids have also been shown to be capable of being utilized in force generation studies as indicators of muscle activity (187). Limitations of scaffold-free assemblies and organoids are long-term culture requirements, small tissue size, biological transport concerns, and challenges with the scale-up feasibility of the technology (137).

\section{Microfluidics and Microchips}

Cell culture through the application of microchip and microfluidic systems, colloquially called "organ on a chip" devices, provides the ability to precisely control culture microenvironment for higher throughput analysis of cellular response and behavior and has great promise in drug screening and disease models (188). Regarding culture duration, 3D microchip cultures of skeletal muscle cells have been used as a viable tool for longer-term skeletal muscle cell culture (189). Microchip models have been able to recapitulate many aspects of skeletal muscle cell activity-including contractibility upon external electrical stimuli (190), skeletal muscle cell migration activity (191), and differentiation into multinucleated skeletal muscle tissue bundles $(189,192)$. Micropatterning microgrooves into microchip culture demonstrated the ability to initiate cytoskeletal and nuclear alignment in a directionally specific manner for more relevant physiological models of skeletal muscle (193). Microfluidic chips have also been able to allow motor neurons to form neuromuscular junction synapses with skeletal muscle cells (194). Limitations of microfluidic and microchip technologies are that there is a lack of native $3 \mathrm{D}$ tissue architecture, limited and complex system geometries, and scale-up fabrication issues (195).

\section{CONCLUSION AND FUTURE DIRECTIONS}

COVID-19 is still a reality that severely impacts society, particularly patients and healthcare professionals. Uncertainty

\section{REFERENCES}

1. Rodríguez-Morales AJ, MacGregor K, Kanagarajah S, Patel D, Schlagenhauf P. Going global - travel and the 2019 novel coronavirus. Travel Med Infect Dis. (2020) 33:101578. doi: 10.1016/j.tmaid.2020.101578 regarding the exact mechanisms that explain the wide range of symptoms and secondary diseases experienced by individuals infected by SARS-CoV-2 has been preventing the medical field from providing adequate treatment to patients. Of special importance in this matter, as shown in this review, is the musculoskeletal system, due to the progressive reports of aggressive skeletal muscle complications associated with COVID-19, mainly sarcopenia, cachexia, rhabdomyolysis, peripheral neuropathy, and Guillain-Barré syndrome. It is believed that these conditions are prompted predominantly by the cytokine storm triggered by SARS-CoV-2, but a few studies have also indicated an association with ACE2 downregulation, hypoxia, direct viral invasion into the skeletal muscle, and physical inactivity. Further research to determine the correlation between these conditions and SARS-CoV-2 infection could drive the development of tailored treatment plans that could mitigate or prevent severe musculoskeletal deterioration in those affected by the virus. Importantly, in vitro $3 \mathrm{D}$ cell culture models are appealing strategies to study the long-term impact of SARS-CoV-2 infection on skeletal muscle. They provide a biomimetic microenvironment with tissue-specific ECM qualities. Furthermore, the interaction among cells and cells with ECM is similar to the natural environment found in vivo. Several bioengineering models were reviewed in this work such as synthetic ECM, decellularized tissues, scaffold-free assembly, organoids, microfluidics, and microchips. Future research should be associated with these technologies to understand the skeletal muscle complications after SARS-CoV-2 infection.

\section{AUTHOR CONTRIBUTIONS}

RS, RU, CP, and ES: conceptualization and funding acquisition. RS: supervision. MS, LM, SS, GL, RS, and CB: writingoriginal draft. MS, LM, SS, GL, RS, CB, RU, CP, and ES: writing-review and editing. $\mathrm{CB}$ and SS: design and prepare figures. All authors contributed to the article and approved the submitted version.

\section{FUNDING}

The authors thank the Fundação de Amparo à Pesquisa do Estado de São Paulo - FAPESP: 2016/20796-2 (RU), 2020/04709-8 (RU), 2018/06088-0 (CP), and 2019/10922-9 (RS); Coordenação de Aperfeiçoamento de Pessoal de Nível Superior CAPES: code 001 (CB), Conselho Nacional de Desenvolvimento Científico e Tecnológico - CNPq: 303035/2018-8 (CP), and 405691/2018-1 (CB); FAPFCMSCSP 2019/2021); and American Heart Association - grant \#19IPLOI34760654/ES/2019 and grant \#20PRE35210399/SS. Available online at: https://covid19.who.int/ (accessed November 14, 2021).

3. Chung JY, Thone MN, Kwon YJ. COVID-19 vaccines: the status and perspectives in delivery points of view. Adv Drug Deliv Rev. (2021) 170:1-25. doi: 10.1016/j.addr.2020.12.011 
4. Klok FA, Kruip MJHA, van der Meer NJM, Arbous MS, Gommers DAMPJ, Kant KM, et al. Incidence of thrombotic complications in critically ill ICU patients with COVID-19. Thromb Res. (2020) 191:1457. doi: 10.1016/j.thromres.2020.04.013

5. Hess DC, Eldahshan W, Rutkowski E. COVID-19-related stroke. Transl Stroke Res. (2020) 11:322-5. doi: 10.1007/s12975-020-0 0818-9

6. Lai C-C, Ko W-C, Lee P-I, Jean S-S, Hsueh P-R. Extra-respiratory manifestations of COVID-19. Int J Antimicrob Agents. (2020) 56:106024. doi: 10.1016/j.ijantimicag.2020.106024

7. Huang C, Huang L, Wang Y, Li X, Ren L, Gu X, et al. 6-month consequences of COVID-19 in patients discharged from hospital: a cohort study. Lancet. (2021) 397:220-32. doi: 10.1016/S0140-6736(20)3 2656-8

8. Piotrowicz K, Gasowski J, Michel J-P, Veronese N. Post-COVID-19 acute sarcopenia: physiopathology and management. Aging Clin Exp Res. (2021) 33:2887-98. doi: 10.1007/s40520-021-01942-8

9. Ramani SL, Samet J, Franz CK, Hsieh C, Nguyen CV, Horbinski C, et al. Musculoskeletal involvement of COVID-19: review of imaging. Skeletal Radiol. (2021) 50:1763-73. doi: 10.1007/s00256-021-03734-7

10. Ali AM, Kunugi H. Skeletal muscle damage in COVID-19: a call for action. Medicina. (2021) 57:372. doi: 10.3390/medicina57040372

11. Brosnahan SB, Jonkman AH, Kugler MC, Munger JS, Kaufman DA. COVID19 and respiratory system disorders: current knowledge, future clinical and translational research questions. Arterioscler Thromb Vasc Biol. (2020) 40:2586-97. doi: 10.1161/ATVBAHA.120.314515

12. Finsterer J, Scorza FA, Scorza CA, Fiorini AC. Peripheral neuropathy in COVID-19 is due to immune-mechanisms, pre-existing risk factors, antiviral drugs, or bedding in the Intensive Care Unit. Arq Neuropsiquiatr. (2021) 79:924-8 doi: 10.1590/0004-282x-anp-2021-0030

13. Caress JB, Castoro RJ, Simmons Z, Scelsa SN, Lewis RA, Ahlawat A, et al. COVID-19-associated Guillain-Barré syndrome: the early pandemic experience. Muscle Nerve. (2020) 62:485-91. doi: 10.1002/mus.27024

14. Legros V, Jeannin P, Burlaud-Gaillard J, Chaze T, Gianetto QG, ButlerBrowne G, et al. Differentiation-dependent susceptibility of human muscle cells to Zika virus infection. PLoS Negl Trop Dis. (2020) 14:e0008282. doi: 10.1371/journal.pntd.0008282

15. Quantin B, Perricaudet LD, Tajbakhsh S, Mandel JL. Adenovirus as an expression vector in muscle cells in vivo. Proc Natl Acad Sci USA. (1992) 89:2581-2584. doi: 10.1073/pnas.89.7.2581

16. Ahmad SS, Ahmad K, Lee EJ, Lee Y-H, Choi I. Implications of insulinlike growth factor-1 in skeletal muscle and various diseases. Cells. (2020) 9:1773. doi: 10.3390/cells9081773

17. Mazzon M, Marsh M. Targeting viral entry as a strategy for broad-spectrum antivirals. F1000Research. (2019) 8:F1000 Faculty Rev-1628. doi: 10.12688/f1000research.19694.1

18. Runyan CE, Welch LC, Lecuona E, Shigemura M, Amarelle L, Abdala-Valencia $\mathrm{H}$, et al. Impaired phagocytic function in CX3CR1+ tissue-resident skeletal muscle macrophages prevents muscle recovery after influenza A virus-induced pneumonia in old mice. Aging Cell. (2020) 19:e13180. doi: 10.1164/ajrccm-conference.2020.201.1_MeetingAbstracts.A2970

19. Lentscher AJ, McCarthy MK, May NA, Davenport BJ, Montgomery SA, Raghunathan $\mathrm{K}$, et al. Chikungunya virus replication in skeletal muscle cells is required for disease development. J Clin Invest. (2020) 130:146678. doi: 10.1172/JCI129893

20. Fukui A, Kawabe N, Hashimoto S, Kamei H, Yoshioka K. Skeletal muscle mass depletion in patients with hepatitis C virus infection. Eur J Gastroenterol Hepatol. (2019) 31:5966. doi: 10.1097/MEG.0000000000001255

21. Ding Y, Wang H, Shen H, Li Z, Geng J, Han H, et al. The clinical pathology of severe acute respiratory syndrome (SARS): a report from China. J Pathol. (2003) 200:282-9. doi: 10.1002/path.1440

22. Leung TW, Wong KS, Hui AC, To KF, Lai ST, Ng WF, et al. Myopathic changes associated with severe acute respiratory syndrome: a postmortem case series. Arch Neurol. (2005) 62:1113-7. doi: 10.1001/archneur.62. 7.1113

23. Tran T, Guardigni V, Pencina KM, Amato AA, Floyd M, Brawley $\mathrm{B}$, et al. Atypical skeletal muscle profiles in human immunodeficiency virus-infected asymptomatic middle-aged adults. Clin Infect Dis. (2018) 66:1918-27. doi: 10.1093/cid/cix1121

24. Sungnak W, Huang N, Bécavin C, Berg M, Queen R, Litvinukova M, et al. SARS-CoV-2 entry factors are highly expressed in nasal epithelial cells together with innate immune genes. Nat Med. (2020) 26:6817. doi: 10.1038/s41591-020-0868-6

25. Shang J, Wan Y, Luo C, Ye G, Geng Q, Auerbach A, et al. Cell entry mechanisms of SARS-CoV-2. Proc Natl Acad Sci USA. (2020) 117:1172734. doi: 10.1073/pnas.2003138117

26. Yuan Y, Cao D, Zhang Y, Ma J, Qi J, Wang Q, et al. Cryo-EM structures of MERS-CoV and SARS-CoV spike glycoproteins reveal the dynamic receptor binding domains. Nat Commun. (2017) 8:15092. doi: 10.1038/ncomms15092

27. Heald-Sargent T, Gallagher T. Ready, set, fuse! The coronavirus spike protein and acquisition of fusion competence. Viruses. (2012) 4:55780. doi: 10.3390/v4040557

28. Belouzard S, Millet JK, Licitra BN, Whittaker GR. Mechanisms of coronavirus cell entry mediated by the viral spike protein. Viruses. (2012) 4:1011-33. doi: 10.3390/v4061011

29. Martinez-Ferran M, de la Guía-Galipienso F, Sanchis-Gomar F, ParejaGaleano H. Metabolic impacts of confinement during the COVID-19 pandemic due to modified diet and physical activity habits. Nutrients. (2020) 12:E1549. doi: 10.3390/nu12061549

30. Walls AC, Park YJ, Tortorici MA, Wall A, McGuire AT, Veesler D. Structure, function, and antigenicity of the SARS-CoV-2 spike glycoprotein. Cell. (2020) 181:281-92. doi: 10.1016/j.cell.2020.02.058

31. Hrenak J, Paulis L, Simko F. Angiotensin A/Alamandine/MrgD Axis: another clue to understanding cardiovascular pathophysiology. Int J Mol Sci. (2016) 17:E1098. doi: 10.3390/ijms17071098

32. Zunke F, Rose-John S. The shedding protease ADAM17: physiology and pathophysiology. Biochimica Et Biophys Acta Mol Cell Res. (2017) 1864:205970. doi: 10.1016/j.bbamcr.2017.07.001

33. Pal R, Bhansali A. COVID-19, diabetes mellitus and ACE2: the conundrum. Diabetes Res Clin Pract. (2020) 162:108132. doi: 10.1016/j.diabres.2020.108132

34. Yamamoto K, Takeshita H, Rakugi H. ACE2, angiotensin 1-7 and skeletal muscle: review in the era of COVID-19. Clin Sci. (2020) 134:304762. doi: 10.1042/CS20200486

35. Yoshida T, Delafontaine P. Mechanisms of IGF-1-mediated regulation of skeletal muscle hypertrophy and atrophy. Cells. (2020) 9:1970. doi: 10.3390/cells9091970

36. Murphy KT, Hossain MI, Swiderski K, Chee A, Naim T, Trieu J, et al. Mas receptor activation slows tumor growth and attenuates muscle wasting in cancer. Cancer Res. (2019) 79:706-19. doi: 10.1158/0008-5472.CAN-181207

37. Morales MG, Abrigo J, Meneses C, Simon F, Cisternas F, Rivera JC, et al. The Ang-(1-7)/Mas-1 axis attenuates the expression and signalling of TGF$\beta 1$ induced by AngII in mouse skeletal muscle. Clin Sci. (2014) 127:25164. doi: 10.1042/CS20130585

38. Morales MG, Abrigo J, Acuña MJ, Santos RA, Bader M, Brandan E, et al. Angiotensin-(1-7) attenuates disuse skeletal muscle atrophy in mice via its receptor, Mas. Dis Models Mech. (2016) 9:441-9. doi: 10.1242/dmm. 023390

39. Márquez-Miranda V, Abrigo J, Rivera JC, Araya-Durán I, Aravena J, Simon F, et al. The complex of PAMAM-OH dendrimer with Angiotensin (17) prevented the disuse-induced skeletal muscle atrophy in mice. Int $J$ Nanomedicine. (2017) 12:1985-99. doi: 10.2147/IJN.S125521

40. Sabharwal R, Cicha MZ, Sinisterra RDM, de Sousa FB, Santos RA, Chapleau MW. Chronic oral administration of Ang-(1-7) improves skeletal muscle, autonomic and locomotor phenotypes in muscular dystrophy. Clin Sci. (2014) 127:101-9. doi: 10.1042/CS20130602

41. Acuña MJ, Pessina P, Olguin H, Cabrera D, Vio CP, Bader M, et al. Restoration of muscle strength in dystrophic muscle by angiotensin-1-7 through inhibition of TGF- $\beta$ signalling. Hum Mol Genet. (2014) 23:123749. doi: $10.1093 / \mathrm{hmg} / \mathrm{ddt} 514$

42. Riquelme C, Acuña MJ, Torrejón J, Rebolledo D, Cabrera D, Santos $\mathrm{RA}$, et al. ACE2 is augmented in dystrophic skeletal muscle and plays a role in decreasing associated fibrosis. PLoS ONE. (2014) 9:e93449. doi: 10.1371/journal.pone.0093449 
43. Miesbach W. Pathological role of angiotensin II in severe COVID-19. TH Open Comp J Thromb Haemost. (2020) 4:e138-44. doi: 10.1055/s-0040-1713678

44. Tay MZ, Poh CM, Rénia L, MacAry PA, Ng LFP. The trinity of COVID19: immunity, inflammation and intervention. Nat Rev Immunol. (2020) 20:363-74. doi: 10.1038/s41577-020-0311-8

45. Ogle ME, Segar CE, Sridhar S, Botchwey EA. Monocytes and macrophages in tissue repair: implications for immunoregenerative biomaterial design. Exp Biol Med. (2016) 241:1084-97. doi: 10.1177/1535370216650293

46. Bersini S, Gilardi M, Mora M, Krol S, Arrigoni C, Candrian C, et al. Tackling muscle fibrosis: from molecular mechanisms to next generation engineered models to predict drug delivery. Adv Drug Deliv Rev. (2018) 129:64-77. doi: 10.1016/j.addr.2018.02.009

47. Hu B, Huang S, Yin L. The cytokine storm and COVID-19. J Med Virol. (2021) 93:250-6. doi: 10.1002/jmv.26232

48. Merad M, Martin JC. Pathological inflammation in patients with COVID19: a key role for monocytes and macrophages. Nat Rev Immunol. (2020) 20:355-62. doi: 10.1038/s41577-020-0331-4

49. Heinonen S, Rodriguez-Fernandez R, Diaz A, Oliva RodriguezPastor S, Ramilo O, Mejias A. Infant immune response to respiratory viral infections. Immunol Allergy Clin North Am. (2019) 39:361-76. doi: 10.1016/j.iac.2019.03.005

50. Kollmann TR, Crabtree J, Rein-Weston A, Blimkie D, Thommai F, Wang $\mathrm{XY}$, et al. Neonatal innate TLR-mediated responses are distinct from those of adults. J Immunol. (2009) 183:7150-60. doi: 10.4049/jimmunol.0901481

51. Siu K-L, Kok K-H, Ng M-HJ, Poon VKM, Yuen K-Y, Zheng B-J, et al. Severe acute respiratory syndrome coronavirus $\mathrm{M}$ protein inhibits type I interferon production by impeding the formation of TRAF3.TANK.TBK1/IKKepsilon complex. J Biol Chem. (2009) 284:16202-9. doi: 10.1074/jbc.M109.008227

52. Azkur AK, Akdis M, Azkur D, Sokolowska M, van de Veen W, Brüggen $\mathrm{M}-\mathrm{C}$, et al. Immune response to SARS-CoV-2 and mechanisms of immunopathological changes in COVID-19. Allergy. (2020) 75:156481. doi: 10.1111/all.14364

53. Conti P, Ronconi G, Caraffa A, Gallenga C, Ross R, Frydas I, et al. Induction of pro-inflammatory cytokines (IL-1 and IL-6) and lung inflammation by Coronavirus-19 (COVI-19 or SARS-CoV-2): anti-inflammatory strategies. J Biol Regulat Homeost Agents. (2020) 34:327-31. doi: 10.23812/CONTI-E

54. Imai Y, Kuba K, Neely GG, Yaghubian-Malhami R, Perkmann T, van Loo $\mathrm{G}$, et al. Identification of oxidative stress and Toll-like receptor 4 signaling as a key pathway of acute lung injury. Cell. (2008) 133:23549. doi: $10.1016 /$ j.cell.2008.02.043

55. Ninomiya S, Nakamura N, Nakamura H, Mizutani T, Kaneda Y, Yamaguchi $\mathrm{K}$, et al. Low levels of serum tryptophan underlie skeletal muscle atrophy. Nutrients. (2020) 12:E978. doi: 10.3390/nu12040978

56. Wang P-Y, Li Y, Wang Q. Sarcopenia: an underlying treatment target during the COVID-19 pandemic. Nutrition. (2021) 84:111104. doi: 10.1016/j.nut.2020.111104

57. Savrun A, Aydin IE, Savrun ST, Karaman U. The predictive role of biomarkers for mortality in COVID-19 patients. Trop Biomed. (2021) 38:366-70. doi: 10.47665/tb.38.3.080

58. Frisoni P, Neri M, D’Errico S, Alfieri L, Bonuccelli D, Cingolani M, et al. Cytokine storm and histopathological findings in 60 cases of COVID-19-related death: from viral load research to immunohistochemical quantification of major players IL-1 $\beta$, IL-6, IL-15 and TNF- $\alpha$. Forensic Sci Med Pathol. (2021). doi: 10.1007/s12024-021-00414-9. [Epub ahead of print].

59. Welch C, Greig C, Masud T, Wilson D, Jackson TA. COVID-19 and acute sarcopenia. Aging Dis. (2020) 11:1345-51. doi: 10.14336/AD.2020.1014

60. Wilkinson DJ, Piasecki M, Atherton PJ. The age-related loss of skeletal muscle mass and function: measurement and physiology of muscle fibre atrophy and muscle fibre loss in humans. Ageing Res Rev. (2018) 47:12332. doi: $10.1016 /$ j.arr.2018.07.005

61. Booth FW, Roberts CK, Thyfault JP, Ruegsegger GN, Toedebusch RG. Role of inactivity in chronic diseases: evolutionary insight and pathophysiological mechanisms. Physiol Rev. (2017) 97:1351-402. doi: 10.1152/physrev.00019.2016

62. Narici M, Vito G de, Franchi M, Paoli A, Moro T, Marcolin G, et al. Impact of sedentarism due to the COVID-19 home confinement on neuromuscular, cardiovascular and metabolic health: physiological and pathophysiological implications and recommendations for physical and nutritional countermeasures. Eur J Sport Sci. (2021) 21:61435. doi: 10.1080/17461391.2020.1761076

63. Martone AM, Bianchi L, Abete P, Bellelli G, Bo M, Cherubini A, et al. The incidence of sarcopenia among hospitalized older patients: results from the Glisten study. J Cachexia Sarcopenia Muscle. (2017) 8:90714. doi: $10.1002 /$ jcsm. 12224

64. Londhe P, Guttridge DC. Inflammation induced loss of skeletal muscle. Bone. (2015) 80:131-42. doi: 10.1016/j.bone.2015.03.015

65. Langen RCJ, Gosker HR, Remels AH v, Schols AMWJ. Triggers and mechanisms of skeletal muscle wasting in chronic obstructive pulmonary disease. Int J Biochem Cell Biol. (2013) 45:2245-56. doi: 10.1016/j.biocel.2013.06.015

66. Zarogoulidis P, Lampaki S, Turner JF, Huang H, Kakolyris S, Syrigos K, et al. mTOR pathway: a current, up-to-date mini-review (review). Oncol Lett. (2014) 8:2367-70. doi: 10.3892/ol.2014.2608

67. Carnac G, Vernus B, Bonnieu A. Myostatin in the pathophysiology of skeletal muscle. Curr Genomics. (2007) 8:415-22. doi: 10.2174/138920207783591672

68. Hoppeler H, Kleinert E, Schlegel C, Claassen H, Howald H, Kayar SR, et al. Morphological adaptations of human skeletal muscle to chronic hypoxia. Int J Sports Med. (1990) 11 (Suppl. 1):S3-9. doi: 10.1055/s-2007-1024846

69. Mizuno T, Fujiki K, Sasakawa A, Hisamoto N, Matsumoto K. Role of the Caenorhabditis elegans Shc adaptor protein in the c-Jun Nterminal kinase signaling pathway. Mol Cell Biol. (2008) 28:70419. doi: 10.1128/MCB.00938-08

70. Morley JE, Anker SD, Evans WJ. Cachexia and aging: an update based on the Fourth International Cachexia Meeting. J Nutr Health Aging. (2009) 13:47-55. doi: 10.1007/s12603-009-0009-x

71. Anker MS, Landmesser U, von Haehling S, Butler J, Coats AJS, Anker SD. Weight loss, malnutrition, and cachexia in COVID-19: facts and numbers. $J$ Cachexia Sarcopenia Muscle. (2021) 12:9-13. doi: 10.1002/jcsm.12674

72. Morley JE, Kalantar-Zadeh K, Anker SD. COVID-19: a major cause of cachexia and sarcopenia? J Cachexia Sarcopenia Muscle. (2020) 11:8635. doi: $10.1002 / \mathrm{jcsm} .12589$

73. Virgens IPA, Santana NM, Lima SCVC, Fayh APT. Can COVID-19 be a risk for cachexia for patients during intensive care? Narrative review and nutritional recommendations. Br J Nutr. (2021) 126:55260. doi: 10.1017/S0007114520004420

74. Li T, Zhang Y, Gong C, Wang J, Liu B, Shi L, et al. Prevalence of malnutrition and analysis of related factors in elderly patients with COVID-19 in Wuhan, China. Eur J Clin Nutr. (2020) 74:871-5. doi: 10.1038/s41430-0200642-3

75. Paliwal VK, Garg RK, Gupta A, Tejan N. Neuromuscular presentations in patients with COVID-19. Neurol Sci. (2020) 41:3039-56. doi: 10.1007/s10072-020-04708-8

76. Lechien JR, Chiesa-Estomba CM, de Siati DR, Horoi M, le Bon SD, Rodriguez A, et al. Olfactory and gustatory dysfunctions as a clinical presentation of mild-to-moderate forms of the coronavirus disease (COVID19): a multicenter European study. Eur Arch Otorhinolaryngol. (2020) 277:2251-61. doi: 10.1007/s00405-020-05965-1

77. Glaubitz S, Schmidt K, Zschüntzsch J, Schmidt J. Myalgia in myositis and myopathies. Best Pract Res Clin Rheumatol. (2019) 33:101433. doi: 10.1016/j.berh.2019.101433

78. Manjavachi MN, Motta EM, Marotta DM, Leite DFP, Calixto JB. Mechanisms involved in IL-6-induced muscular mechanical hyperalgesia in mice. Pain. (2010) 151:345-55. doi: 10.1016/j.pain.2010.07.018

79. Lippi G, Wong J, Henry BM. Myalgia may not be associated with severity of coronavirus disease 2019 (COVID-19). World J Emerg Med. (2020) 11:1934. doi: 10.5847/wjem.j.1920-8642.2020.03.013

80. Drozdzal S, Rosik J, Lechowicz K, Machaj F, Szostak B, Majewski P, et al. COVID-19: pain management in patients with SARS-CoV-2 infectionmolecular mechanisms, challenges, and perspectives. Brain Sci. (2020) 10:E465. doi: 10.3390/brainsci10070465

81. Kucuk A, Cumhur Cure M, Cure E. Can COVID-19 cause myalgia with a completely different mechanism? A hypothesis. Clin Rheumatol. (2020) 39:2103-04. doi: 10.1007/s10067-020-05178-1

82. Queme LF, Ross JL, Jankowski MP. Peripheral mechanisms of ischemic myalgia. Front Cell Neurosci. (2017) 11:419. doi: 10.3389/fncel.2017.00419 
83. Saud A, Naveen R, Aggarwal R, Gupta L. COVID-19 and myositis: what we know so far. Curr Rheumatol Rep. (2021) 23:63. doi: 10.1007/s11926-021-01023-9

84. Beydon M, Chevalier K, al Tabaa O, Hamroun S, Delettre A-S, Thomas M, et al. Myositis as a manifestation of SARS-CoV-2. Ann Rheum Dis. (2020). doi: 10.1136/annrheumdis-2020-217573. [Epub ahead of print].

85. Mughal MS, Kaur IP, Alhashemi R, Rehman R, Du D. Acute viral myositis complicated by rhabdomyolysis: a sole manifestation of COVID19 infection. J Commun Hosp Intern Med Perspect. (2021) 11:28991. doi: 10.1080/20009666.2021.1878601

86. Gokhale Y, Patankar A, Holla U, Shilke M, Kalekar L, Karnik ND, et al. Dermatomyositis during COVID-19 pandemic (a case series): is there a cause effect relationship. J Assoc Physicians India. (2020) 68:20-4.

87. Megremis S, Walker TDJ, He X, Ollier WER, Chinoy H, Hampson L, et al. Antibodies against immunogenic epitopes with high sequence identity to SARS-CoV-2 in patients with autoimmune dermatomyositis. Ann Rheum Dis. (2020) 79:1383-6. doi: 10.1136/annrheumdis-2020-217522

88. Giannini M, Ohana M, Nespola B, Zanframundo G, Geny B, Meyer A. Similarities between COVID-19 and anti-MDA5 syndrome: what can we learn for better care? Eur Respir J. (2020) 56:2001618. doi: 10.1183/13993003.01618-2020

89. Pinal-Fernandez I, Casal-Dominguez M, Derfoul A, Pak K, Plotz P, Miller FW, et al. Identification of distinctive interferon gene signatures in different types of myositis. Neurology. (2019) 93:e1193-204. doi: 10.1212/WNL.0000000000008128

90. Aschman T, Schneider J, Greuel S, Meinhardt J, Streit S, Goebel H-H, et al. Association between SARS-CoV-2 infection and immune-mediated myopathy in patients who have died. JAMA Neurol. (2021) 78:94860. doi: 10.1001/jamaneurol.2021.2004

91. Alrubaye R, Choudhury H. Severe rhabdomyolysis in a 35-year-old woman with COVID-19 due to SARS-CoV-2 infection: a case report. Am J Case Rep. (2020) 21:e926733. doi: 10.12659/AJCR.926733

92. Mukherjee A, Ghosh R, Aftab G. Rhabdomyolysis in a patient with coronavirus disease 2019. Cureus. (2020) 12:e8956. doi: 10.7759/cureus.8956

93. Finsterer J, Scorza F. SARS-CoV-2 associated rhabdomyolysis in 32 patients. Turkish J Med Sci. (2021) 51:1598-1601. doi: 10.3906/sag-2012-327

94. Dres M, Goligher EC, Heunks LMA, Brochard LJ. Critical illnessassociated diaphragm weakness. Intensive Care Med. (2017) 43:144152. doi: 10.1007/s00134-017-4928-4

95. Hooijman PE, Beishuizen A, Witt CC, de Waard MC, Girbes ARJ, Spoelstrade Man AME, et al. Diaphragm muscle fiber weakness and ubiquitinproteasome activation in critically ill patients. Am J Respir Crit Care Med. (2015) 191:1126-38. doi: 10.1164/rccm.201412-2214OC

96. Siao P, Kaku M. A clinician's approach to peripheral neuropathy. Semin Neurol. (2019) 39:519-30. doi: 10.1055/s-0039-1694747

97. Doughty CT, Seyedsadjadi R. Approach to peripheral neuropathy for the primary care clinician. Am J Med. (2018) 131:10106. doi: 10.1016/j.amjmed.2017.12.042

98. Diamond KB, Weisberg MD, Ng MK, Erez O, Edelstein D. COVID-19 peripheral neuropathy: A report of three cases. Cureus. (2021) 13:e18132. doi: $10.7759 /$ cureus. 18132

99. Bureau BL, Obeidat A, Dhariwal MS, Jha P. Peripheral neuropathy as a complication of SARS-Cov-2. Cureus. (2020) 12:e11452. doi: 10.7759/cureus.11452

100. Algahtani H, Subahi A, Shirah B. Neurological complications of middle east respiratory syndrome coronavirus: a report of two cases and review of the literature. Case Rep Neurol Med. (2016) 2016:3502683. doi: $10.1155 / 2016 / 3502683$

101. Nejad JH, Heiat M, Hosseini MJ, Allahyari F, Lashkari A, Torabi $\mathrm{R}$, et al. Guillain-Barré syndrome associated with COVID-19: a case report study. J Neurovirol. (2021) 27:802-5. doi: 10.1007/s13365-02100984-y

102. Dalakas MC. Guillain-Barré syndrome: the first documented COVID19-triggered autoimmune neurologic disease: more to come with myositis in the offing. Neurol Neuroimmunol Neuroinflamm. (2020) 7:e781. doi: 10.1212/NXI.0000000000000781

103. Zubair AS, McAlpine LS, Gardin T, Farhadian S, Kuruvilla DE, Spudich S. Neuropathogenesis and neurologic manifestations of the coronaviruses in the age of coronavirus disease 2019: a review. JAMA Neurol. (2020) 77:1018-27. doi: 10.1001/jamaneurol.2020.2065

104. Chen X, Laurent S, Onur OA, Kleineberg NN, Fink GR, Schweitzer F, et al. A systematic review of neurological symptoms and complications of COVID-19. J Neurol. (2021) 268:392-402. doi: 10.1007/s00415-020-10067-3

105. Ftiha F, Shalom M, Jradeh H. Neurological symptoms due to coronavirus disease 2019. Neurol Int. (2020) 12:8639. doi: 10.4081/ni.2020.8639

106. Keyhanian K, Umeton RP, Mohit B, Davoudi V, Hajighasemi F, Ghasemi M. SARS-CoV-2 and nervous system: from pathogenesis to clinical manifestation. J Neuroimmunol. (2020) 350:577436. doi: 10.1016/j.jneuroim.2020.577436

107. Zhao H, Shen D, Zhou H, Liu J, Chen S. Guillain-Barré syndrome associated with SARS-CoV-2 infection: causality or coincidence? Lancet Neurol. (2020) 19:383-4. doi: 10.1016/S1474-4422(20)30109-5

108. Hussain FS, Eldeeb MA, Blackmore D, Siddiqi ZA. Guillain Barré syndrome and COVID-19: possible role of the cytokine storm. Autoimmun Rev. (2020) 19:102681. doi: 10.1016/j.autrev.2020.102681

109. Kamel WA, Ismail II, Al-Hashel JY. Guillain-Barre syndrome following COVID-19 infection: first case report from Kuwait and review of the literature. Dubai Med J. (2021) 4:42-6. doi: 10.1159/000513382

110. Palaiodimou L, Stefanou M-I, Katsanos AH, Fragkou PC, Papadopoulou M, Moschovos C, et al. Prevalence, clinical characteristics and outcomes of Guillain-Barré syndrome spectrum associated with COVID-19: a systematic review and meta-analysis. Eur J Neurol. (2021) 28:351729. doi: 10.1111/ene. 14860

111. Fantini J, di Scala C, Chahinian H, Yahi N. Structural and molecular modelling studies reveal a new mechanism of action of chloroquine and hydroxychloroquine against SARS-CoV-2 infection. Int J Antimicrob Agents. (2020) 55:105960. doi: 10.1016/j.ijantimicag.2020.105960

112. Dalakas MC, Quarles RH. Autoimmune ataxic neuropathies (sensory ganglionopathies): are glycolipids the responsible autoantigens? Ann Neurol. (1996) 39:419-22. doi: 10.1002/ana.410390402

113. Gandhi RT. The multidimensional challenge of treating coronavirus disease 2019 (COVID-19): remdesivir is a foot in the door. Clin Infect Dis. (2021) 73:e4175-8. doi: 10.1093/cid/ciaa1132

114. Beck MA. Antioxidants and viral infections: host immune response and viral pathogenicity. J Am Coll Nutr. (2001) 20:384S-8S. doi: 10.1080/07315724.2001.10719172

115. Crump KE, Langston PK, Rajkarnikar S, Grayson JM. Antioxidant treatment regulates the humoral immune response during acute viral infection. J Virol. (2013) 87:2577-86. doi: 10.1128/JVI.02714-12

116. McAnulty LS, Nieman DC, Dumke CL, Shooter LA, Henson DA, Utter AC, et al. Effect of blueberry ingestion on natural killer cell counts, oxidative stress, and inflammation prior to and after $2.5 \mathrm{~h}$ of running. Appl Physiol Nutr Metab. (2011) 36:976-84. doi: 10.1139/h11-120

117. Haghikia A, Jörg S, Duscha A, Berg J, Manzel A, Waschbisch A, et al. Dietary fatty acids directly impact central nervous system autoimmunity via the small intestine. Immunity. (2015) 43:817-29. doi: 10.1016/j.immuni.2015. 09.007

118. Hart PH, Gorman S, Finlay-Jones JJ. Modulation of the immune system by UV radiation: more than just the effects of vitamin D? Nat Rev Immunol. (2011) 11:584-96. doi: 10.1038/nri3045

119. Phan TX, Jaruga B, Pingle SC, Bandyopadhyay BC, Ahern GP. Intrinsic photosensitivity enhances motility of T lymphocytes. Sci Rep. (2016) 6:39479. doi: 10.1038/srep39479

120. Holick MF, MacLaughlin JA, Clark MB, Holick SA, Potts JT, Anderson RR, et al. Photosynthesis of previtamin D3 in human skin and the physiologic consequences. Science. (1980) 210:203-5. doi: 10.1126/science.6251551

121. Campbell JP, Turner JE. Debunking the myth of exercise-induced immune suppression: redefining the impact of exercise on immunological health across the lifespan. Front Immunol. (2018) 9:648. doi: 10.3389/fimmu.2018.00648

122. Nieman DC, Wentz LM. The compelling link between physical activity and the body's defense system. J Sport Health Sci. (2019) 8:20117. doi: 10.1016/j.jshs.2018.09.009

123. Nieman DC. Coronavirus disease-2019: a tocsin to our aging, unfit, corpulent, and immunodeficient society. J Sport Health Sci. (2020) 9:293301. doi: 10.1016/j.jshs.2020.05.001 
124. Huh JY. The role of exercise-induced myokines in regulating metabolism. Arch Pharm Res. (2018) 41:14-29. doi: 10.1007/s12272-017-0994-y

125. Filgueira TO, Castoldi A, Santos LER, de Amorim GJ, de Sousa Fernandes MS, Anastácio $\mathrm{W}$ de $\mathrm{L}$ do $\mathrm{N}$, et al. The relevance of a physical active lifestyle and physical fitness on immune defense: mitigating disease burden, with focus on COVID-19 consequences. Front Immunol. (2021) 12:587146. doi: 10.3389/fimmu.2021.587146

126. Spielmann G, McFarlin BK, O'Connor DP, Smith PJW, Pircher H, Simpson RJ. Aerobic fitness is associated with lower proportions of senescent blood T-cells in man. Brain Behav Immun. (2011) 25:15219. doi: 10.1016/j.bbi.2011.07.226

127. Duggal NA, Pollock RD, Lazarus NR, Harridge S, Lord JM. Major features of immunesenescence, including reduced thymic output, are ameliorated by high levels of physical activity in adulthood. Aging Cell. (2018) 17:e12750. doi: 10.1111/acel.12750

128. Wang C, Li W, Drabek D, Okba NMA, van Haperen R, Osterhaus ADME, et al. A human monoclonal antibody blocking SARS-CoV-2 infection. Nat Commun. (2020) 11:2251. doi: 10.1038/s41467-020-16256-y

129. Yan Z, Spaulding HR. Extracellular superoxide dismutase, a molecular transducer of health benefits of exercise. Redox Biol. (2020) 32:101508. doi: 10.1016/j.redox.2020.101508

130. da Silveira MP, da Silva Fagundes KK, Bizuti MR, Starck É, Rossi RC, de Resende E, et al. Physical exercise as a tool to help the immune system against COVID-19: an integrative review of the current literature. Clin Exp Med. (2021) 21:15-28. doi: 10.1007/s10238-020-00650-3

131. Simpson RJ, Katsanis E. The immunological case for staying active during the COVID-19 pandemic. Brain Behav Immun. (2020) 87:67. doi: 10.1016/j.bbi.2020.04.041

132. Sim Y-J, Yu S, Yoon K-J, Yoon KJ, Loiacono CM, Kohut ML. Chronic exercise reduces illness severity, decreases viral load, and results in greater antiinflammatory effects than acute exercise during influenza infection. J Infect Dis. (2009) 200:1434-42. doi: 10.1086/606014

133. Zbinden-Foncea H, Francaux M, Deldicque L, Hawley JA. Does high cardiorespiratory fitness confer some protection against proinflammatory responses after infection by SARS-CoV-2? Obesity. (2020) 28:137881. doi: 10.1002/oby.22849

134. Nieman DC, Henson DA, Austin MD, Sha W. Upper respiratory tract infection is reduced in physically fit and active adults. Br J Sports Med. (2011) 45:987-92. doi: 10.1136/bjsm.2010.077875

135. Gleeson M, Bishop NC, Stensel DJ, Lindley MR, Mastana SS, Nimmo MA. The anti-inflammatory effects of exercise: mechanisms and implications for the prevention and treatment of disease. Nat Rev Immunol. (2011) 11:607-15. doi: 10.1038/nri3041

136. Nieman DC. Is infection risk linked to exercise workload? Med Sci Sports Exerc. (2000) 32:S406-11. doi: 10.1097/00005768-200007001-00005

137. Khodabukus A, Prabhu N, Wang J, Bursac N. In vitro tissue-engineered skeletal muscle models for studying muscle physiology and disease. Adv Healthc Mater. (2018) 7:e1701498. doi: 10.1002/adhm.2017 01498

138. Partridge TA. The mdx mouse model as a surrogate for Duchenne muscular dystrophy. FEBS J. (2013) 280:4177-4186. doi: 10.1111/febs.12267

139. Rodrigues M, Echigoya Y, Fukada S-I, Yokota T. Current translational research and murine models for duchenne muscular dystrophy. $J$ Neuromuscl Dis. (2016) 3:29-48. doi: 10.3233/JND-150113

140. Juhas M, Ye J, Bursac N. Design, evaluation, and application of engineered skeletal muscle. Methods. (2016) 99:81-90. doi: 10.1016/j.ymeth.2015.10.002

141. Engler AJ, Griffin MA, Sen S, Bonnemann CG, Sweeney HL, Discher DE. Myotubes differentiate optimally on substrates with tissue-like stiffness. J Cell Biol. (2004) 166:877-87. doi: 10.1083/jcb.200405004

142. Rao L, Qian Y, Khodabukus A, Ribar T, Bursac N. Engineering human pluripotent stem cells into a functional skeletal muscle tissue. Nat Commun. (2018) 9:126. doi: 10.1038/s41467-017-02636-4

143. Vandenburgh HH, Karlisch P, Farr L. Maintenance of highly contractile tissue-cultured avian skeletal myotubes in collagen gel. In Vitro Cell Dev Biol. (1988) 24:166-74. doi: 10.1007/BF02623542

144. Khodabukus A, Baar K. Regulating fibrinolysis to engineer skeletal muscle from the C2C12 cell line. Tissue Eng Part C Methods. (2009) 15:50111. doi: $10.1089 /$ ten.tec.2008.0286
145. Tang X, Daneshmandi L, Awale G, Nair LS, Laurencin CT. Skeletal muscle regenerative engineering. Regen Eng Trans Med. (2019) 5:23351. doi: 10.1007/s40883-019-00102-9

146. Hudecki A, Kiryczyński G, Łos MJ. Chapter 7 - biomaterials, definition, overview. In: Łos MJ, Hudecki A, Wiecheć E, editors. Stem Cells and Biomaterials for Regenerative Medicine. Cambridge: Academic Press (2019). p. 85-98.

147. Fuoco C, Petrilli LL, Cannata S, Gargioli C. Matrix scaffolding for stem cell guidance toward skeletal muscle tissue engineering. JOrthop Surg Res. (2016) 11:86. doi: 10.1186/s13018-016-0421-y

148. Boldrin L, Elvassore N, Malerba A, Flaibani M, Cimetta E, Piccoli M, et al. Satellite cells delivered by micro-patterned scaffolds: A new strategy for cell transplantation in muscle diseases. Tissue Eng. (2007) 13:253-62. doi: $10.1089 /$ ten.2006.0093

149. Khaing ZZ, Schmidt CE. Advances in natural biomaterials for nerve tissue repair. Neurosci Lett. (2012) 519:103-14. doi: 10.1016/j.neulet.2012.02.027

150. Murakami K, Aoki H, Nakamura S, Nakamura S, Takikawa M, Hanzawa M, et al. Hydrogel blends of chitin/chitosan, fucoidan and alginate as healing-impaired wound dressings. Biomaterials. (2010) 31:83-90. doi: 10.1016/j.biomaterials.2009.09.031

151. Meinel L, Kaplan DL. Silk constructs for delivery of musculoskeletal therapeutics. Adv Drug Deliv Rev. (2012) 64:1111-22. doi: 10.1016/j.addr.2012.03.016

152. Boontheekul T, Hill EE, Kong H-J, Mooney DJ. Regulating myoblast phenotype through controlled gel stiffness and degradation. Tissue Eng. (2007) 13:1431-1442. doi: 10.1089/ten.2006.0356

153. Hill E, Boontheekul T, Mooney DJ. Designing scaffolds to enhance transplanted myoblast survival and migration. Tissue Eng. (2006) 12:1295304. doi: 10.1089/ten.2006.12.1295

154. Hill E, Boontheekul T, Mooney DJ. Regulating activation of transplanted cells controls tissue regeneration. Proc Nat Acad Sci. (2006) 103:24949. doi: $10.1073 /$ pnas. 0506004103

155. Borselli C, Storrie H, Benesch-Lee F, Shvartsman D, Cezar C, Lichtman JW, et al. Functional muscle regeneration with combined delivery of angiogenesis and myogenesis factors. Proc Nat Acad Sci. (2010) 107:328792. doi: $10.1073 /$ pnas.0903875106

156. Brady MA, Lewis MP, Mudera V. Synergy between myogenic and nonmyogenic cells in a $3 \mathrm{D}$ tissue-engineered craniofacial skeletal muscle construct. J Tissue Eng Regen Med. (2008) 2:408-17. doi: 10.1002/ term. 112

157. Vandenburgh H, Shansky J, Benesch-Lee F, Barbata V, Reid J, Thorrez L, et al. Drug-screening platform based on the contractility of tissue-engineered muscle. Muscle Nerve. (2008) 37:438-47. doi: 10.1002/mus.20931

158. Mechanical stimulation improves tissue-engineered human skeletal muscle. Am J Physiol Cell Physiol. (2002) 283:C155765. doi: 10.1152/ajpcell.00595.2001

159. Shansky J, Chromiak J, del Tatto M, Vandenburgh H. A simplified method for tissue engineering skeletal muscle organoids in vitro. In Vitro Cell Dev Biol Anim. (1997) 33:659-61. doi: 10.1007/s11626-997-0118-y

160. Okano T, Matsuda T. Hybrid muscular tissues: preparation of skeletal muscle cell-incorporated collagen gels. Cell Transplant. (1997) 6:10918. doi: 10.1177/096368979700600204

161. Okano T, Satoh S, Oka T, Matsuda T. Tissue engineering of skeletal muscle. Highly dense, highly oriented hybrid muscular tissues biomimicking native tissues. ASAIO J. (1997) 43:M74953. doi: 10.1097/00002480-199703000-00060

162. Hinds S, Bian W, Dennis RG, Bursac N. The role of extracellular matrix composition in structure and function of bioengineered skeletal muscle. Biomaterials. (2011) 32:3575-83. doi: 10.1016/j.biomaterials.2011.01.062

163. Grefte S, Vullinghs S, Kuijpers-Jagtman AM, Torensma R, Hoff JWV den. Matrigel, but not collagen I, maintains the differentiation capacity of muscle derived cells in vitro. Biomed Mater. (2012) 7:55004. doi: 10.1088/1748-6041/7/5/055004

164. Mosesson MW. Fibrinogen and fibrin structure and functions. J Thromb Haemost. (2005) 3:1894-904. doi: 10.1111/j.1538-7836.2005.01365.x

165. Grassl ED, Oegema TR, Tranquillo RT. Fibrin as an alternative biopolymer to type-I collagen for the fabrication of a media equivalent. J Biomed Mater Res. (2002) 60:607-12. doi: 10.1002/jbm.10107 
166. Collet J-P, Shuman H, Ledger RE, Lee S, Weisel JW. The elasticity of an individual fibrin fiber in a clot. Proc Nat Acad Sci. (2005) 102:91337. doi: 10.1073/pnas.0504120102

167. Yang L, van der Werf KO, Koopman BF, Subramaniam V, Bennink ML, Dijkstra PJ, et al. Micromechanical bending of single collagen fibrils using atomic force microscopy. J Biomed Mater Res Part A. (2007) 82:1608. doi: 10.1002/jbm.a.31127

168. Sakiyama SE, Schense JC, Hubbell JA. Incorporation of heparin-binding peptides into fibrin gels enhances neurite extension: an example of designer matrices in tissue engineering. FASEB J. (1999) 13:221424. doi: 10.1096/fasebj.13.15.2214

169. Dietrich F, Lelkes PI. Fine-tuning of a three-dimensional microcarrierbased angiogenesis assay for the analysis of endothelial-mesenchymal cell co-cultures in fibrin and collagen gels. Angiogenesis. (2006) 9:11125. doi: 10.1007/s10456-006-9037-x

170. Qazi TH, Mooney DJ, Pumberger M, Geissler S, Duda GN. Biomaterials based strategies for skeletal muscle tissue engineering: existing technologies and future trends. Biomaterials. (2015) 53:502-21. doi: 10.1016/j.biomaterials.2015.02.110

171. Wolf MT, Daly KA, Reing JE, Badylak SF. Biologic scaffold composed of skeletal muscle extracellular matrix. Biomaterials. (2012) 33:291625. doi: 10.1016/j.biomaterials.2011.12.055

172. Valentin JE, Turner NJ, Gilbert TW, Badylak SF. Functional skeletal muscle formation with a biologic scaffold. Biomat. (2010) 31:7475-84. doi: 10.1016/j.biomaterials.2010.06.039

173. Machingal MA, Corona BT, Walters TJ, Kesireddy V, Koval CN, Dannahower A, et al. A tissue-engineered muscle repair construct for functional restoration of an irrecoverable muscle injury in a murine model. Tissue Eng Part A. (2011) 17:2291-303. doi: 10.1089/ten.tea.2010.0682

174. Corona BT, Ward CL, Baker HB, Walters TJ, Christ GJ. Implantation of in vitro tissue engineered muscle repair constructs and bladder acellular matrices partially restore in vivo skeletal muscle function in a rat model of volumetric muscle loss injury. Tissue Eng Part A. (2014) 20:70515. doi: 10.1089/ten.tea.2012.0761

175. Urciuolo A, de Coppi P. Decellularized tissue for muscle regeneration. Int J Mol Sci. (2018) 19:2392. doi: 10.3390/ijms19082392

176. Bian W, Bursac N. Engineered skeletal muscle tissue networks with controllable architecture. Biomaterials. (2009) 30:140112. doi: 10.1016/j.biomaterials.2008.11.015

177. Li B, Lin M, Tang Y, Wang B, Wang JH-C. A novel functional assessment of the differentiation of micropatterned muscle cells. J Biomech. (2008) 41:3349-53. doi: 10.1016/j.jbiomech.2008.09.025

178. Huang NF, Patel S, Thakar RG, Wu J, Hsiao BS, Chu B, et al. Myotube assembly on nanofibrous and micropatterned polymers. Nano Lett. (2006) 6:537-42. doi: 10.1021/nl060060o

179. Clark P, Dunn GA, Knibbs A, Peckham M. Alignment of myoblasts on ultrafine gratings inhibits fusion in vitro. Int J Biochem Cell Biol. (2002) 34:816-25. doi: 10.1016/S1357-2725(01)00180-7

180. Evans DJ, Britland S, Wigmore PM. Differential response of fetal and neonatal myoblasts to topographical guidance cues in vitro. Dev Genes Evol. (1999) 209:438-42. doi: 10.1007/s004270050275

181. Takahashi H, Shimizu T, Nakayama M, Yamato M, Okano T. The use of anisotropic cell sheets to control orientation during the self-organization of 3D muscle tissue. Biomaterials. (2013) 34:7372-80. doi: 10.1016/j.biomaterials.2013.06.033

182. Nagamori E, Ngo TX, Takezawa Y, Saito A, Sawa Y, Shimizu T, et al. Network formation through active migration of human vascular endothelial cells in a multilayered skeletal myoblast sheet. Biomaterials. (2013) 34:6628. doi: 10.1016/j.biomaterials.2012.08.055

183. Takahashi H, Okano T. Cell Sheet-based tissue engineering for organizing anisotropic tissue constructs produced using microfabricated thermoresponsive substrates. Adv Healthc Mater. (2015) 4:2388-407. doi: 10.1002/adhm.201500194

184. Faustino Martins J-M, Fischer C, Urzi A, Vidal R, Kunz S, Ruffault P-L, et al. Self-organizing 3D human trunk neuromuscular organoids. Cell Stem Cell. (2020) 26:172-86.e6. doi: 10.1016/j.stem.2019.12.007

185. Gholobova D, Terrie L, Gerard M, Declercq H, Thorrez L. Vascularization of tissue-engineered skeletal muscle constructs. Biomaterials. (2020) 235:119708. doi: 10.1016/j.biomaterials.2019.119708

186. Maffioletti SM, Sarcar S, Henderson ABH, Mannhardt I, Pinton L, Moyle LA, et al. Three-dimensional human iPSC-derived artificial skeletal muscles model muscular dystrophies and enable multilineage tissue engineering. Cell Rep. (2018) 23:899-908. doi: 10.1016/j.celrep.2018. 03.091

187. Cheema U, Yang S-Y, Mudera V, Goldspink GG, Brown RA. 3-D in vitro model of early skeletal muscle development. Cell Motility Cytoskeleton. (2003) 54:226-36. doi: 10.1002/cm.10095

188. Wnorowski A, Yang H, Wu JC. Progress, obstacles, and limitations in the use of stem cells in organ-on-a-chip models. Adv Drug Deliv Rev. (2019) 140:3-11. doi: 10.1016/j.addr.2018.06.001

189. Tourovskaia A, Figueroa-Masot X, Folch A. Differentiation-on-a-chip: a microfluidic platform for long-term cell culture studies. Lab Chip. (2005) 5:14-9. doi: 10.1039/b405719h

190. Shimizu K, Araki H, Sakata K, Tonomura W, Hashida M, Konishi S. Microfluidic devices for construction of contractile skeletal muscle microtissues. J Biosci Bioeng. (2015) 119:2126. doi: 10.1016/j.jbiosc.2014.07.003

191. Roveimiab Z, Lin F, Anderson JE. Emerging development of microfluidicsbased approaches to improve studies of muscle cell migration. Tissue Eng Part B Rev. (2019) 25:30-45. doi: 10.1089/ten.teb.2018.0181

192. Agrawal G, Aung A, Varghese S. Skeletal muscle-on-a-chip: an in vitro model to evaluate tissue formation and injury. Lab Chip. (2017) 17:344761. doi: 10.1039/C7LC00512A

193. Anene-Nzelu CG, Peh KY, Fraiszudeen A, Kuan YH, Ng SH, Toh YC, et al. Scalable alignment of three-dimensional cellular constructs in a microfluidic chip. Lab Chip. (2013) 13:4124-33. doi: 10.1039/c3lc50730k

194. Southam KA, King AE, Blizzard CA, McCormack GH, Dickson TC. Microfluidic primary culture model of the lower motor neuron-neuromuscular junction circuit. J Neurosci Methods. (2013) 218:164-9. doi: 10.1016/j.jneumeth.2013.06.002

195. Probst C, Schneider S, Loskill P. High-throughput organ-on-a-chip systems: current status and remaining challenges. Curr Opin Biomed Eng. (2018) 6:33-41. doi: 10.1016/j.cobme.2018.02.004

Conflict of Interest: The authors declare that the research was conducted in the absence of any commercial or financial relationships that could be construed as a potential conflict of interest.

Publisher's Note: All claims expressed in this article are solely those of the authors and do not necessarily represent those of their affiliated organizations, or those of the publisher, the editors and the reviewers. Any product that may be evaluated in this article, or claim that may be made by its manufacturer, is not guaranteed or endorsed by the publisher.

Copyright (C) 2022 Seixas, Mitre, Shams, Lanzuolo, Bartolomeo, Silva, Prado, Ureshino and Stilhano. This is an open-access article distributed under the terms of the Creative Commons Attribution License (CC BY). The use, distribution or reproduction in other forums is permitted, provided the original author(s) and the copyright owner(s) are credited and that the original publication in this journal is cited, in accordance with accepted academic practice. No use, distribution or reproduction is permitted which does not comply with these terms. 